Canadian

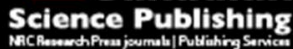

Canadian Geotechnical Journal Revue canadienne de géotechnique

\title{
A new interaction model for the vertical dynamic response of pipe piles considering soil plug effect
}

\begin{tabular}{|r|l|}
\hline Journal: & Canadian Geotechnical Journal \\
\hline Manuscript ID & cgj-2016-0309.R2 \\
\hline Danuscript Type: & Article \\
\hline Complete List of Authors: & $\begin{array}{l}\text { Wu, Wenbing; China University of Geosciences } \\
\text { El Naggar, M. Hesham; University of Western Ontario, } \\
\text { Abdlrahem, Maged; Geotechnical Research Centre, Faculty of Engineering, } \\
\text { The University of Western Ontario } \\
\text { Mei, Guoxiong; Nanjing University of Technology } \\
\text { Wang, Kui-hua; Zhejiang University, Research Center of Coastal and Urban } \\
\text { Geotechnical Engineering }\end{array}$ \\
\hline Keyword: & $\begin{array}{l}\text { pile vibration, soil plug effect, additional mass model, Apparent Wave } \\
\text { Velocity of Pipe Pile, pile integrity testing }\end{array}$ \\
\hline \multicolumn{2}{|c}{} \\
\hline
\end{tabular}




\title{
A new interaction model for the vertical dynamic response of pipe
}

\section{piles considering soil plug effect}

\author{
Wenbing Wu ${ }^{\mathrm{a}, \mathrm{b}, \mathrm{c}}$, M. Hesham El Naggar ${ }^{\mathrm{b}}$, Maged Abdlrahem ${ }^{\mathrm{b}}$, Guoxiong Mei ${ }^{\mathrm{c}^{*}}$, Kuihua Wang ${ }^{\mathrm{d}}$ \\ ${ }^{a}$ Engineering Research Centre of Rock-Soil Drilling \& Excavation and Protection, Ministry of Education, \\ China University of Geosciences, Wuhan, Hubei 430074, China \\ ${ }^{b}$ Geotechnical Research Centre, Faculty of Engineering, The University of Western Ontario, London, ON, \\ N6A 5B9, Canada \\ ${ }^{c}$ Key Laboratory of Disaster Prevention and Structural Safety of Ministry of Education, College of Civil \\ Engineering and Architecture, Guangxi University, Nanning, Guangxi 530004, China \\ ${ }^{d}$ Research Center of Coastal and Urban Geotechnical Engineering, Zhejiang University, Hangzhou, \\ Zhejiang 310058, China
}

\begin{abstract}
A soil pile interaction model is developed to better represent the actual behavior of pipe piles undergoing dynamic testing. In order to correctly investigate the dynamic interaction mechanism of the pipe piles, the developed model introduces an additional mass to account for soil plug. The governing equations of motion for the soil-pile system subjected to small deformations and stains are established considering plane strain conditions for the soil and one-dimensional wave propagation in the pile. The analytical solution of the vertical dynamic response of the pipe pile in the frequency domain is then obtained by employing Laplace transform and transfer function technique. The corresponding quasi-analytical solution in the time domain for the pipe pile subjected to a vertical semi-sinusoidal exciting force is subsequently derived by means of Fourier transform. A parameter sensitivity analysis of the additional mass model is carried out to determine the approximate range of the parameters value. Utilizing the developed solution, a parametric study is performed to illustrate the influence of the properties of soil-pile system on the vertical dynamic response of pipe pile. Finally, the validity of the additional mass model has been validated by conducting a set of model tests, based on which the concept of Apparent Wave Velocity of Pipe Pile (AWVPP) is also proposed.
\end{abstract}

Keywords: pile vibration; soil plug effect; additional mass model; Apparent Wave Velocity of Pipe Pile; pile integrity testing 


\section{Introduction}

The use of pipe piles is becoming increasingly popular for supporting various structures all over the world. Therefore, the mechanical response of pipe piles under static and dynamic loading has attracted increasing attention in recent years. Compared with solid cross-section piles, the interaction mechanism between soil and pipe piles is more complicated, especially for open-ended pipe piles due to the formation of a soil column inside the pile (known as soil plug) during the driving process (Matsumoto and Takei 1991; Gavin and Lehane 2003; Sakr et al. 2004; Ko and Jeong 2015). The existence of a soil plug inside the pipe pile gives rise to some challenges when evaluating the pile's static and dynamic behavior. For example, $\mathrm{Wu}$ (2012) observed that the estimated velocity of longitudinal stress waves propagating in the driven pipe piles before low-strain integrity testing could not be simply set as the average longitudinal wave velocity of pile material, but it decreased as the height of the soil plug increased. In addition, the height of the soil plug will affect the shaft resistance to static loads. It also affects the dynamic behavior of the pipe pile when subjected to dynamic loads. Therefore, better understanding of the interaction mechanism between soil plug and pipe pile is a key factor to explain the observed dynamic response of pipe pile.

The investigation of the dynamic response of pipe piles provides the theoretical basis for drivability analysis and various method of dynamic pile testing. Many studies in the field of drivability analysis of pipe piles were focused on developing the dynamic interaction model of the soil plug-pipe pile system to simulate the soil plug effect during the driving process. The existing dynamic interaction models fall into four main categories: Firstly, the equivalent mass model (Kraft et al. 1981), in which the weight of soil plug segment is added to the weight of corresponding pipe pile segment. This model can take into account the influence of soil plug weight on the drivability of pipe pile, but it ignores the dynamic interaction between the soil plug and the pipe pile. Secondly, the plugging effect model (Yan et al. 2009), which considers the open-ended pipe pile as a closed-end pipe pile when the soil plug height is ten times the diameter of pipe pile. Nevertheless, this model overlooks the fact that the effect of the soil plug is a function of the diameter of pipe pile. Thirdly, the Voigt model (Liu et al. 2005), which simulates the contact interaction of the soil plug and the pipe pile by utilizing a linear spring and a dashpot connected in parallel. The Voigt model can consider the dynamic interaction of the soil plug and the pipe pile, but it cannot account for the influence of soil plug weight on the dynamic response of pipe pile. Finally, the "pile 
within a pile" model (Randolph and Simons 1986; Matsumoto et al. 1991; Liyanapathirana et al. 2001), in which the soil plug is modeled as a series of masses and springs. It can be deduced that shear stresses along the interface between the soil plug and the internal wall of the pipe pile also result in vertical shear waves propagating along the radial direction towards the central axis of the soil plug. Meanwhile, the vertical shear waves in the soil plug will cause stress waves up and down the soil plug due to its cylindrical configuration. Therefore, the "pile within a pile" is a more rigorous interaction model than the three above-mentioned models for it can take into account both the soil weight and the frictional resistance between soil plug segments and pipe pile segments. However, this model doe not consider the damping effect of the stress wave propagating in the soil plug.

Several approaches have been developed to establish a theoretical basis for interpreting dynamic pipe pile testing results. For instance, Chen and Luo (2004) employed the finite element method to investigate the influence of the pipe pile diameter on the reflected wave signal. Several researchers have examined three-dimensional effects of pipe pile dynamic response and their influence on the evaluation of PCC and PHC pile integrity by adopting the finite element method and finite difference method (e.g. Huang and Chen 2005; Fei et al. 2007). Ding et al. (2011) and Zheng et al. (2015, 2016) presented a computational method for the vertical dynamic response of a large-diameter pipe pile subjected to a transient point loading. Following this approach, Liu et al. (2014) further investigated the vertical dynamic response of a pipe pile embedded in saturated soil based on the dynamic consolidation theory of Biot. Lu et al. (2013) addressed the three-dimensional characteristics of wave propagation in pipe piles by using elastodynamic finite integration technique. In all these investigations, the influence of soil plug effect on the dynamic response of pipe pile, which may result in reflected wave signals at the top surface of soil plug, has been ignored.

In this paper, a new soil-pile interaction model, named the additional mass model, is proposed to simulate the dynamic interaction of the soil plug and pipe pile system. The theoretical solutions of the vertical dynamic response of pipe piles in the frequency and time domains are derived by applying Laplace transforms and the transfer function technique. Using the derived solutions, a parametric study has been undertaken to portray the influence of pipe pile and soil plug properties on the pile vertical dynamic response. Based on the results of the parametric study, the concept of Apparent Wave Velocity of Pipe Pile (AWVPP) is proposed in this paper. The concept of AWVPP is of great importance in the interpretation of the results of non-destructive testing of piles. Finally, the theoretical model has been verified by comparing 
the model predictions with results obtained from model tests.

\section{Analytical Model}

\section{Conceptual model and assumptions}

The proposed dynamic interaction model for the vertical vibration of a pipe pile embedded in layered soil is shown in Fig. 1. The soil-pile system is divided into $n$ segments or layers in the vertical direction that are marked by $1,2, \ldots, j, \ldots, n$ from pile bottom to pile head. This allows varying the pile modulus or cross-section and soil properties. The pipe pile and soil layer properties are assumed to be homogeneous within each segment or layer, respectively, but may vary from segment to segment or layer to layer. According to the coordinate system shown in Fig. $1, l_{j}$ and $h_{j}$ denote the thickness and depth of the $j$ th $(1 \leq j \leq n)$ layer, respectively. The pile length is $\mathrm{H}$ and its outer and inner radii are $r_{1}$ and $r_{2}$, respectively. The height of soil plug is $H_{\mathrm{s}}$. The frictional force of the $j$ th surrounding soil layer acting on the outer surface of the $j$ th pipe pile segment shaft is depicted as $f_{j}$, which can be expressed as $f_{j}=K_{j} u_{\mathrm{p}, j}(z, t)$, where $K_{j}$ is the vertical shear complex stiffness of the $j$ th soil layer around the shaft of the $j$ th pipe pile segment and $u_{\mathrm{p}, j}(z, t)$ is the vertical displacement of the $j$ th pipe pile segment, respectively.

To consider the dynamic interaction between the pile and soil plug, the additional mass model is established as described in Fig. 1. The basic idea of the additional mass model is that the vertical dynamic displacement of the soil plug is different than that of the pipe pile, that is, the soil plug and pipe pile vibrations are out-of-phase and the inertial force acting on the soil plug is caused by the difference between the vertical dynamic displacements of pile and soil plug. The unit mass of the $j$ th soil plug layer is denoted by $m_{\mathrm{s}, j}$, which is regarded as additional mass of the pile. The additional mass $m_{\mathrm{s}, j}$ is connected to the $j$ th pile segment by means of the distributed Voigt model, in which the spring constant and damping coefficient are represented by $k_{j}$ and $\eta_{j}$, respectively. For each pile segment above the soil plug, it is only required that $m_{\mathrm{s}, j}=0$, then the assumptions of the additional mass model can be satisfied.

The main assumptions adopted in the proposed model are as follows:

(1) The pipe pile is vertical with annular cross-section, is in perfect contact with the surrounding soil 
during vibration and its material is viscoelastic.

(2) The surrounding soil is viscoelastic, with arbitrarily stratified layers along the pile shaft, extending infinitely in the radial direction. The soil top surface is assumed to be free boundary (i.e. zero normal and shear stresses). The stresses and displacements of the soil approach zero at an infinite radial distance.

(3) The dynamic stress of the surrounding soil is transferred to the pile outer wall through the vertical shear complex stiffness on the contact interface of soil-pile system.

(4) The soil-pile system is subjected to small deformations and strains during vibration.

(5) At the beginning of vibration, the displacement and velocity of the soil plug are zero.

\section{Equations of motion}

Governing equation of the soil

Assuming the surrounding soil layer consisting of independent infinitesimally thin horizontal layers extending to infinity and ignoring the stress gradient in the vertical direction (Novak 1974; El Naggar and Novak 1994), the dynamic equilibrium equation of soil motion in axisymmetric cylindrical coordinates can be formulated as:

$$
r^{2} \frac{\mathrm{d}^{2} W_{j}(r)}{\mathrm{d} r^{2}}+r \frac{\mathrm{d} W_{j}(r)}{\mathrm{d} r}-\beta_{j j}^{2} r^{2} W_{j}(r)=0(j=1,2, \ldots \ldots, n)
$$

where $W_{j}(r)$ denotes the vertical displacement of the $j$ th soil layer. $\beta_{j}=\frac{\mathrm{i} \omega}{v_{j} \sqrt{1+\mathrm{i} D_{j}}}$, in which $v_{j}=\sqrt{G_{j} / \rho_{j}}$ is the shear wave velocity of the $j$ th soil layer. $\rho_{j}, G_{j}$ and $D_{j}$ represent the mass density, shear modulus and material damping of the $j$ th soil layer, respectively. $\omega$ is the angular frequency and $i=\sqrt{-1}$ is imaginary unit.

\section{Governing equation of the pipe pile}

Denoting $u_{\mathrm{s}, j}(z, t)$ as the vertical displacement of the $j$ th soil plug layer, the dynamic governing equations of the soil plug and the pipe pile can be derived as:

Dynamic equation of the $j$ th soil plug layer:

$$
\begin{aligned}
& m_{\mathrm{s}, j} \frac{\mathrm{d}^{2} u_{\mathrm{s}, j}(z, t)}{\mathrm{d} t^{2}}-2 \pi r_{2} k_{j}\left[u_{\mathrm{p}, j}(z, t)-u_{\mathrm{s}, j}(z, t)\right]-2 \pi r_{2} \eta_{j} \frac{\mathrm{d}\left[u_{\mathrm{p}, j}(z, t)-u_{\mathrm{s}, j}(z, t)\right]}{\mathrm{d} t}=0 \\
& (j=1,2, \ldots \ldots, n)
\end{aligned}
$$

Dynamic equation of the $j$ th pipe pile segment: 


$$
\begin{aligned}
& E_{\mathrm{p}, j} A_{2} \frac{\partial^{2} u_{\mathrm{p}, j}(z, t)}{\partial z^{2}}+\delta_{\mathrm{p}, j} A_{2} \frac{\partial^{3} u_{\mathrm{p}, j}(z, t)}{\partial t \partial z^{2}}-\rho_{\mathrm{p}, j} A_{2} \frac{\partial^{2} u_{\mathrm{p}, j}(z, t)}{\partial t^{2}}-f_{j}- \\
& 2 \pi r_{2} k_{j}\left[u_{\mathrm{p}, j}(z, t)-u_{\mathrm{s}, j}(z, t)\right]-2 \pi r_{2} \eta_{j} \frac{\partial\left[u_{\mathrm{p}, j}(z, t)-u_{\mathrm{s}, j}(z, t)\right]}{\partial t}=0(j=1,2, \ldots \ldots, n)
\end{aligned}
$$

where $E_{\mathrm{p}, j}=\rho_{\mathrm{p}, j} V_{\mathrm{p}, j}^{2}, \quad A_{2}=\pi\left(r_{1}^{2}-r_{2}^{2}\right), \quad \rho_{\mathrm{p}, j}, \quad V_{\mathrm{p}, j}$ and $\delta_{\mathrm{p}, j}$ indicate the elastic modulus, cross-section area, density, longitudinal wave velocity and material damping coefficient of the $j$ th pipe pile segment, respectively.

\section{Boundary and initial conditions of the soil-pile system}

(1) Boundary conditions of the pipe pile:

At the pile head:

$$
\left.\left[E_{\mathrm{p}, n} A_{2} \frac{\partial u_{\mathrm{p}, n}(z, t)}{\partial z}+\delta_{\mathrm{p}, n} A_{2} \frac{\partial^{2} u_{\mathrm{p}, n}(z, t)}{\partial t \partial z}\right]\right|_{z=0}=-q(t)
$$

At the pile toe:

$$
\left.\left[E_{\mathrm{p}, 1} \frac{\partial u_{\mathrm{p}, 1}(z, t)}{\partial z}+\delta_{\mathrm{p}, 1} \frac{\partial^{2} u_{\mathrm{p}, 1}(z, t)}{\partial t \partial z}+k_{\mathrm{b}} u_{\mathrm{p}, 1}(z, t)+\eta_{\mathrm{b}} \frac{\partial u_{\mathrm{p}, 1}(z, t)}{\partial t}\right]\right|_{z=H}=0
$$

where $q(t)$ is the harmonic excitation acting on the pile head. $k_{\mathrm{b}}$ and $\eta_{\mathrm{b}}$ are used to denote the distributed spring constant and damping coefficient per unit area at the bottom of the pipe pile, respectively. The value of $k_{\mathrm{b}}$ and $\eta_{\mathrm{b}}$ can be obtained via the equations presented by Lysmer and Richart(1966) as:

$$
\begin{aligned}
& k_{\mathrm{b}}=\frac{4 G_{\mathrm{b}} r_{1}}{A_{1}\left(1-v_{\mathrm{b}}\right)} \\
& \eta_{\mathrm{b}}=\frac{3.4 G_{\mathrm{b}} r_{1}^{2}}{A_{1} V_{\mathrm{b}}\left(1-v_{\mathrm{b}}\right)}
\end{aligned}
$$

where $G_{\mathrm{b}}=\rho_{\mathrm{b}} V_{\mathrm{b}}^{2}, \rho_{\mathrm{b}}, V_{\mathrm{b}}$ and $v_{\mathrm{b}}$ denote the shear modulus, mass density, shear wave velocity and Poisson's ratio of soil at pile toe, respectively. $A_{1}=\pi r_{1}^{2}$ is the total cross-sectional coverage area of pipe pile.

At the interface of the pile segments:

$$
\left\{\begin{array}{l}
\left.u_{\mathrm{p}, j}(z, t)\right|_{z=h_{j}}=\left.u_{\mathrm{p}, j+1}(z, t)\right|_{z=h_{j}} \\
{\left.\left[E_{\mathrm{p}, j} A_{2} \frac{\partial u_{\mathrm{p}, j}(z, t)}{\partial z}+\delta_{\mathrm{p}, j} A_{2} \frac{\partial^{2} u_{\mathrm{p}, j}(z, t)}{\partial z \partial t}\right]\right|_{z=h_{j}}=\left.\left[E_{\mathrm{p}, j+1} A_{2} \frac{\partial u_{\mathrm{p}, j+1}(z, t)}{\partial z}+\delta_{\mathrm{p}, j+1} A_{2} \frac{\partial^{2} u_{\mathrm{p}, j+1}(z, t)}{\partial z \partial t}\right]\right|_{z=h_{j}}}
\end{array}\right.
$$


(2) Initial conditions of the soil-pile system:

Initial conditions for the soil plug:

$$
\left\{\begin{array}{l}
\left.u_{\mathrm{s}, j}(z, t)\right|_{t=0}=0 \\
\left.\frac{\partial u_{\mathrm{s}, j}(z, t)}{\partial t}\right|_{t=0}=0
\end{array}(j=1,2, \ldots \ldots, n)\right.
$$

Initial conditions for the pipe pile:

$$
\left\{\begin{array}{l}
\left.u_{\mathrm{p}, j}(z, t)\right|_{t=0}=0 \\
\left.\frac{\partial u_{\mathrm{p}, j}(z, t)}{\partial t}\right|_{t=0}=0
\end{array}(j=1,2, \ldots \ldots, n)\right.
$$

\section{Solution of Equations of Motion}

\section{Vibration of Soil Layers}

The general solution of Eq. (1) can be expressed in terms of Bessel Functions as:

$$
W_{j}(r)=a_{j} \mathrm{~K}_{0}\left(\beta_{j} r\right)+b_{j} \mathrm{I}_{0}\left(\beta_{j} r\right)(j=1,2, \ldots \ldots, n)
$$

where $\mathrm{I}_{0}(\cdot)$ and $\mathrm{K}_{0}(\cdot)$ represent the modified Bessel functions of order zero of the first and second kinds, respectively; $a_{j}$ and $b_{j}$ are undetermined constants, which can be obtained by considering the boundary conditions. Considering the boundary condition at the ground surface (zero normal and shear stresses), Eq. (11) yields $b_{j}=0$.

The vertical shear stress amplitude at any point within the $j$ th soil layer can be derived as:

$$
\tau_{j}(r)=G_{j}^{*} \frac{\mathrm{d} W_{j}(r)}{\mathrm{d} r}=-G_{j}^{*} a_{j} \beta_{j} \mathrm{~K}_{1}\left(\beta_{j} r\right)(j=1,2, \ldots \ldots, n)
$$

where $G_{j}^{*}=G_{j}\left(1+\mathrm{i} D_{j}\right) ; \mathrm{K}_{1}(\cdot)$ is the modified Bessel function of order one of the second kind.

The vertical shear complex stiffness of the $j$ th soil layer around the $j$ th pile segment can then be obtained as:

$$
\begin{aligned}
K_{j} & =\frac{-2 \pi r_{1} \tau_{j}\left(r_{1}\right)}{W_{j}\left(r_{1}\right)} \\
& =2 \pi r_{1} G_{j}^{*} \beta_{j} \mathrm{~K}_{1}\left(\beta_{j} r_{1}\right) / \mathrm{K}_{0}\left(\beta_{j} r_{1}\right)(j=1,2, \ldots \ldots, n)
\end{aligned}
$$

\section{Vertical vibration of the pipe pile}

The Laplace Transform with respect to time of $u_{\mathrm{p}, j}(z, t)$ and $u_{\mathrm{s}, j}(z, t)$ are defined as: 


$$
\begin{aligned}
& U_{\mathrm{p}, j}(z, s)=\int_{0}^{\infty} u_{\mathrm{p}, j}(z, s) \mathrm{e}^{-s \mathrm{t}} \mathrm{dt} \\
& U_{\mathrm{s}, j}(z, s)=\int_{0}^{\infty} u_{\mathrm{s}, j}(z, s) \mathrm{e}^{-s t} \mathrm{dt}
\end{aligned}
$$

where $s$ is the Laplace transform parameter. Combining with the initial conditions (9) and (10) and taking the Laplace transform of Eq. (2) (two-side) yields:

$$
U_{\mathrm{s}, j}(z, s)=\frac{2 \pi r_{2}\left(k_{j}+\eta_{j} \cdot s\right)}{m_{\mathrm{s} j} s^{2}+2 \pi r_{2}\left(k_{j}+\eta_{j} \cdot s\right)} U_{\mathrm{p}, j}(z, s)(j=1,2, \ldots \ldots, n)
$$

Combining Eq. (13) and Eqs. (9) and (10) (i.e. initial conditions), and applying the Laplace transform to Eq. (3) gives:

$$
\begin{aligned}
& E_{\mathrm{p}, j} A_{2} \frac{\partial^{2} U_{\mathrm{p}, j}(z, s)}{\partial z^{2}}+\delta_{\mathrm{p}, j} A_{2} \cdot s \frac{\partial^{2} U_{\mathrm{p}, j}(z, s)}{\partial z^{2}}-\rho_{\mathrm{p}, j} A_{2} s^{2} U_{\mathrm{p}, j}(z, s)-K_{j} U_{\mathrm{p}, j}(z, s)- \\
& 2 \pi r_{2}\left(k_{j}+\eta_{j} \cdot s\right)\left[U_{\mathrm{p}, j}(z, s)-U_{\mathrm{s}, j}(z, s)\right]=0(j=1,2, \ldots \ldots, n)
\end{aligned}
$$

Substituting Eq. (16) into Eq. (17), the dynamic equation of the $j$ th pile segment can be further reduced as:

$$
V_{\mathrm{p}, j}^{2}\left(1+\frac{\delta_{\mathrm{p}, j}}{E_{\mathrm{p}, j}} s\right) \frac{\partial^{2} U_{\mathrm{p}, j}(z, s)}{\partial^{2} z}-\left(s^{2}+\frac{K_{j}+K_{\mathrm{s}, j}}{\rho_{\mathrm{p}, j} A_{2}}\right) U_{\mathrm{p}, j}(z, s)=0(j=1,2, \ldots \ldots, n)
$$

where $K_{\mathrm{s}, j}$ represents the vertical shear complex stiffness of soil plug acting on the $j$ th pile segment, which can be written as:

$$
K_{\mathrm{s}, j}=\frac{2 \pi r_{2}\left(k_{j}+\eta_{j} \cdot s\right) m_{\mathrm{s}, j} s^{2}}{m_{\mathrm{s}, j} s^{2}+2 \pi r_{2}\left(k_{j}+\eta_{j} \cdot s\right)}
$$

The general solution of Eq. (18) can be derived as:

$$
U_{\mathrm{p}, j}(z, s)=c_{j} \cos \left(\bar{\lambda}_{j} z / l_{j}\right)+d_{j} \sin \left(\bar{\lambda}_{j} z / l_{j}\right)(j=1,2, \ldots \ldots, n)
$$

where $c_{j}$ and $d_{j}$ are complex constants determined by considering the boundary conditions, and $\bar{\lambda}_{j}$ is dimensionless eigenvalue, which can be expressed as:

$$
\bar{\lambda}_{j}=\sqrt{-\frac{\left(s^{2}+\frac{K_{j}+K_{\mathrm{s}, j}}{\rho_{\mathrm{p}, j} A_{2}} t_{j}{ }^{2}\right.}{1+\frac{\delta_{\mathrm{p}, j}}{E_{\mathrm{p}, j}} s}}(j=1,2, \ldots \ldots, n)
$$

where $t_{j}=l_{j} / V_{\mathrm{p}, j}$ represents the propagation time of elastic longitudinal wave in the $j$ th pile segment.

Based on the definition presented by Wang et al. (2010), the displacement impedance function at the top 
of the first pipe pile segment $\left(z=h_{1}\right)$ can be derived as:

$$
\begin{aligned}
\left.Z_{\mathrm{p}, 1}\right|_{z=h_{1}} & =\frac{-\left.\left[E_{\mathrm{p}, 1} A_{2} \frac{\partial U_{\mathrm{p}, 1}(z, s)}{\partial z}+\delta_{\mathrm{p}, 1} A_{2} \frac{\partial U_{\mathrm{p}, 1}(z, s)}{\partial z}\right]\right|_{z=h_{1}}}{\left.U_{\mathrm{p}, 1}(z, s)\right|_{z=h_{1}}} \\
& =-\frac{\rho_{\mathrm{p}, 1} A_{2} V_{\mathrm{p}, 1}\left(1+\frac{\delta_{\mathrm{p}, 1}}{E_{\mathrm{p}, 1}} s\right) \bar{\lambda}_{1} \tan \left(\bar{\lambda}_{1}-\phi_{1}\right)}{t_{1}}
\end{aligned}
$$

where $\phi_{1}=\arctan \frac{Z_{\mathrm{p}, 0} t_{1}}{\rho_{\mathrm{p}, 1} A_{2} V_{\mathrm{p}, 1} \bar{\lambda}_{1}\left(1+\frac{\delta_{\mathrm{p}, 1}}{E_{\mathrm{p}, 1}} s\right)} \cdot Z_{\mathrm{p}, 0}$ is the displacement function at the pile toe, which can be obtained by considering the boundary condition (5).

The method of recursion (see Wang et al. $(2010)$ and Wu et al. $(2014,2016)$ ) can then be used to obtain the displacement impedance function at the top of the $j$ th pipe pile segment, i.e.:

$$
\begin{aligned}
\left.Z_{\mathrm{p}, j}\right|_{z=h_{j}} & =\frac{-\left.\left[E_{\mathrm{p}, j} A_{2} \frac{\partial U_{\mathrm{p}, j}(z, s)}{\partial z}+\delta_{\mathrm{p}, j} A_{2} \frac{\partial U_{\mathrm{p}, j}(z, s)}{\partial z}\right]\right|_{z=h_{j}}}{\left.U_{\mathrm{p}, j}(z, s)\right|_{z=h_{j}}} \\
& =-\frac{\rho_{\mathrm{p}, j} A_{2} V_{\mathrm{p}, j}\left(1+\frac{\delta_{\mathrm{p}, j}}{E_{\mathrm{p}, j}} s\right) \bar{\lambda}_{j} \tan \left(\bar{\lambda}_{j}-\phi_{j}\right)}{t_{j}}
\end{aligned}
$$

where $\phi_{j}=\arctan \frac{Z_{\mathrm{p}, j-1} t_{j}}{\rho_{\mathrm{p}, j} A_{2} V_{\mathrm{p}, j} \bar{\lambda}_{j}\left(1+\frac{\delta_{\mathrm{p}, j}}{E_{\mathrm{p}, j}} s\right)} \cdot Z_{\mathrm{p}, j-1}$ is used to describe the displacement impedance function at the top of the (j-1)th pile segment, which can be determined from Eq. (22) by using the method of recursion.

Through further recursion, the displacement impedance function at the pile head can be derived as:

$$
\begin{aligned}
\left.Z_{\mathrm{p}, n}\right|_{z=h_{n}=0} & =\frac{-\left.\left[E_{\mathrm{p}, n} A_{2} \frac{\partial U_{\mathrm{p}, n}(z, s)}{\partial z}+\delta_{\mathrm{p}, n} A_{2} \frac{\partial U_{\mathrm{p}, n}(z, s)}{\partial z}\right]\right|_{z=0}}{\left.U_{\mathrm{p}, n}(z, s)\right|_{z=0}} \\
& =-\frac{\rho_{\mathrm{p}, n} A_{2} V_{\mathrm{p}, n}}{t_{n}}\left(1+\frac{\delta_{\mathrm{p}, n}}{E_{\mathrm{p}, n}} s\right) \bar{\lambda}_{n} \tan \left(\bar{\lambda}_{n}-\phi_{n}\right)
\end{aligned}
$$

where $\phi_{n}=\arctan \frac{Z_{\mathrm{p}, n-1} t_{n}}{\rho_{\mathrm{p}, n} A_{2} V_{\mathrm{p}, n} \bar{\lambda}_{n}\left(1+\frac{\delta_{\mathrm{p}, n}}{E_{\mathrm{p}, n}} S\right)}$. 
Following the definition of Wang et al. (2010), the velocity transform function at the pile head can be expressed as:

$$
\begin{aligned}
& H_{u}=s \times \frac{1}{Z_{\mathrm{p}, n}} \\
& =-\frac{s \cdot t_{n}}{\rho_{\mathrm{p}, n} A_{2} V_{\mathrm{p}, n}\left(1+\frac{\delta_{\mathrm{p}, n}}{E_{\mathrm{p}, n}} s\right) \bar{\lambda}_{n} \tan \left(\bar{\lambda}_{n}-\phi_{n}\right)}
\end{aligned}
$$

Letting $s=\mathrm{i} \omega$ and substituting it into Eq. (25), the velocity response in the frequency domain at the pile head can be derived as:

$$
H_{v}=-\frac{1}{\rho_{\mathrm{p}, n} A_{2} V_{\mathrm{p}, n}} H_{v}^{\prime}
$$

where $H_{v}^{\prime}$ denotes the dimensionless velocity admittance of the pile head, which can be expressed as:

$$
H_{v}^{\prime}=\frac{\mathrm{i} \bar{\omega} \bar{t}_{n}}{\left(1+\frac{\delta_{\mathrm{p}, n}}{E_{\mathrm{p}, n} T_{\mathrm{c}}} \mathrm{i} \bar{\omega}\right) \bar{\lambda}_{n} \tan \left(\bar{\lambda}_{n}-\phi_{n}\right)}
$$

where $\bar{\omega}=T_{\mathrm{c}} \omega$ and $\bar{t}_{n}=t_{n} / T_{\mathrm{c}}$ represent the dimensionless frequency and dimensionless propagation time of elastic longitudinal waves in the $n$th pipe pile segment, respectively; and $T_{\mathrm{c}}$ indicates the total propagation time of elastic longitudinal waves in the pile.

By virtue of the inverse Fourier transform, the velocity response at the pile head can be obtained in the time domain as $V(t)=\operatorname{IFT}\left[Q(\omega) H_{v}(\mathrm{i} \omega)\right]$, where $Q(\omega)$ denotes the Fourier transform of $q(t)$ with respect to time. In particular, for low-strain integrity testing of pipe piles, the vertical excitation acting on the pile head can be regarded as a semi-sinusoidal force given by:

$$
q(t)=\left\{\begin{array}{l}
Q_{\max } \sin \frac{\pi t}{T_{0}}, t \in\left(0, T_{0}\right) \\
0, \quad t \geq T_{0}
\end{array}\right.
$$

where $T_{0}$ and $Q_{\max }$ are the impulse width and maximum amplitude of the excitation. The velocity response in the time domain at the pile head can then be derived as:

$$
V(t)=\frac{Q_{\max }}{\rho_{\mathrm{p}, n} A_{2} V_{\mathrm{p}, n}} V_{v}^{\prime}
$$


where $V_{v}^{\prime}$ is used to define the dimensionless velocity response in the time domain which can be expressed as:

$$
V_{v}^{\prime}=-\frac{1}{2} \int_{-\infty}^{\infty} \frac{\mathrm{i} \bar{\omega} \bar{t}_{n}}{\left(1+\mathrm{i} \frac{\delta_{\mathrm{p}, n}}{E_{\mathrm{p}, n} T_{\mathrm{c}}} \bar{\omega}\right) \bar{\lambda}_{n} \tan \left(\bar{\lambda}_{n}-\phi_{n}\right)} \frac{\bar{T}_{0}}{\pi^{2}-\bar{T}_{0}^{2} \bar{\omega}^{2}}\left(1+\mathrm{e}^{-\mathrm{i} \bar{\omega} \bar{T}_{0}}\right) \mathrm{e}^{\mathrm{i} \bar{\omega} \bar{t}} \mathrm{~d} \bar{\omega}
$$

where $\bar{T}_{0}=T_{0} / T_{\mathrm{c}}$ and $\bar{t}=t / T_{\mathrm{c}}$ are the dimensionless pulse width and dimensionless time variable, respectively.

\section{Parameter sensitivity analysis of the additional mass model}

The boundary conditions of the soil plug are different from that of the soil surrounding the pipe pile. Hence the parameter values of the distributed Voigt model (two main parameters of the additional mass model) can not be simply determined by utilizing the equations presented for the dynamic Kelvin-Voigt model at the interface of pile and surrounding soil. Therefore, there is a need to investigate the sensitivity range for the distributed Voigt model parameters based on the function properties of the solutions. Following the derivation process, it is worth noting that the dynamic interaction between the soil plug and the pile shaft can be mainly reflected by $K_{\mathrm{s}, j}$, expressed in Eq. (19). For convenience, Eq.(19) is rewritten as:

$$
K_{\mathrm{s}, j}=\rho_{\mathrm{s}, j} \pi r_{2}^{2} s^{2}-\frac{\left(\rho_{\mathrm{s}, j} \pi r_{2}^{2} s^{2}\right)^{2}}{\rho_{\mathrm{s}, j} \pi r_{2}^{2} s^{2}+2 \pi r_{2}\left(k_{j}+\eta_{j} \cdot s\right)}
$$

Eq. (31) demonstrates that $K_{\mathrm{s}, j}$ is a function of four parameters: material characteristic parameter $\rho_{\mathrm{s}, j}$; geometry parameter $r_{2}$; Laplace transform parameter $s$; and distributed Voigt model parameters $k_{j}$ and $\eta_{j}$. It is worth mentioning that $\rho_{\mathrm{s}, j}$ and $r_{2}$ can be obtained by measurements and $s$ can be determined according to the excitation frequency, that is to say, $\rho_{\mathrm{s}, j}, r_{2}$ and $s$ can be regarded as known variables. Therefore, $K_{\mathrm{s}, j}$ is a hyperbolic function having $k_{j}$ and $\eta_{j}$ as independent variables. The hyperbolic function has two notable characteristics: (1) When $k_{j}$ and $\eta_{j}$ approach zero, $K_{\mathrm{s}, j}=0$, which means that the soil plug does not participate in the pile vibration; (2) When $k_{j}$ and $\eta_{j}$ tend to positive infinite, it is $K_{\mathrm{s}, j}=\rho_{\mathrm{s}, j} \pi r_{2}^{2} s^{2}$, which indicates that the soil plug and the pipe pile vibrate 
together. For most practical applications, the values of $k_{j}$ and $\eta_{j}$ lie between these two extreme cases. It can also be concluded that the values of $k_{j}$ and $\eta_{j}$ may have a significant impact on the coupled vibration characteristics of the pipe pile and the soil plug. In view of this, the sensitivity range of the distributed Voigt model parameters is discussed in detail by utilizing numerical inversion method under different conditions.

Condition 1: The sensitivity range of $k_{j}$ and $\eta_{j}$ is evaluated for different values of Laplace transform constant and pile inner radius, i.e.: $s=1,5,10 ; r_{2}=0.3 \mathrm{~m}, 0.5 \mathrm{~m}, 0.7 \mathrm{~m} ; \rho_{\mathrm{s}, j}=1800 \mathrm{~kg} / \mathrm{m}^{3}$.

It is evident from Figs. 2, 3 and 4 that $K_{\mathrm{s}, j}$ increases with the increase of the pile inner radius, which indicates that the effect of the dynamic interaction of the pipe pile and the soil plug becomes more prominent due to the increased soil plug mass. As the pile inner radius increases, the sensitivity range of the spring constant also increases, but the range of the damping coefficient remains basically unchanged. It can also be observed that the Laplace transform constant has a remarkable effect on the parameters of the distributed Voigt model, that is, the range for both the spring constant and damping coefficient increases with an increase in Laplace transform constant.

Condition 2: The sensitivity range of $k_{j}$ and $\eta_{j}$ is analyzed for different values of the Laplace transform constant and of the density of the soil plug, i.e., $s=1,5,10$; $\rho_{\mathrm{s}, j}=1600 \mathrm{~kg} / \mathrm{m}^{3}, 1800 \mathrm{~kg} / \mathrm{m}^{3}, 2000 \mathrm{~kg} / \mathrm{m}^{3} ; r_{2}=0.5 \mathrm{~m}$

Figs. 5, 6 and 7 demonstrate that $K_{\mathrm{s}, j}$ increases as the soil plug density increases and that the effect of soil plug density on the spring constant and damping coefficient is negligible. However, for this condition, the range of spring constant and damping coefficient also increases as the Laplace transform constant increases.

Based on these observations, three conclusions can be drawn from this parameter sensitivity analysis: (1) The spring constant $k_{j}$ is mainly affected by the pile inner radius and the Laplace transform constant $s$; (2) The damping coefficient is only influenced by the Laplace transform constant $s$, and consequently the excitation frequency; and (3) The spring constant and damping coefficient can be preliminarily assumed to lie within the range of $(0 \sim 900) \mathrm{kN} \cdot \mathrm{m}^{-3}$ and $(0 \sim 300) \mathrm{kN} \cdot \mathrm{m}^{-3} \cdot \mathrm{s}$, respectively. 
The influence of the distributed Voigt model on the vertical dynamic response of the pipe pile is explored by evaluating the velocity admittance curve and the reflected wave signal curve of the pipe pile (employing Eqs. (27) and (30)). The parameters used in this analysis are: (1) the pile length, outer radius, thickness, density and longitudinal wave velocity are equal to $15 \mathrm{~m}, 0.4 \mathrm{~m}, 0.12 \mathrm{~m}, 2500 \mathrm{~kg} / \mathrm{m}^{3}$ and $4000 \mathrm{~m} / \mathrm{s}$, respectively; (2) the soil profile is divided into two layers: the first layer is along the pile shaft and the second layer extends from the pile toe to the end of the soil profile. The density, shear wave velocity and Poisson's ratio of soil below pile toe are equal to $2000 \mathrm{~kg} / \mathrm{m}^{3}, 220 \mathrm{~m} / \mathrm{s}$ and 0.35 , respectively, and the corresponding properties for soil along the shaft are equal to $1800 \mathrm{~kg} / \mathrm{m}^{3}$ and $120 \mathrm{~m} / \mathrm{s}, 0.35$, respectively. The height, density and shear wave velocity of soil plug are equal to $5 \mathrm{~m}, 1800 \mathrm{~kg} / \mathrm{m}^{3}$ and $120 \mathrm{~m} / \mathrm{s}$, respectively.

Fig. 8 shows the influence of the spring constant of the distributed Voigt model on the vertical dynamic response of the pipe pile when the damping coefficient of the distributed Voigt model is equal to zero. It is clear from Fig. 8a that for a spring constant value lower than $100 \mathrm{kN} \cdot \mathrm{m}^{-3}$, the velocity admittance curve is oscillatory with a uniform resonant peak, which decreases slightly as the spring constant increases within this low value range. However, for $k_{2}>100 \mathrm{kN} \cdot \mathrm{m}^{-3}$ the oscillation displays nonuniform peaks from cycle to cycle indicating a strong effect of the soil plug. Fig. $8 \mathrm{a}$ also shows that variation of the resonant frequency of the velocity admittance curve is negligible. Meanwhile, Fig. $8 \mathrm{~b}$ shows that the reflected wave signal curve is relatively flat with no reflected signal at the location of the top surface of soil plug. It is also noted that the peak amplitude of the reflected signal at the pile toe decreases slightly as the spring constant increases. On the other hand, for $k_{2}>100 \mathrm{kN} \cdot \mathrm{m}^{-3}$, small resonant peaks are observed. In addition, reverse reflected signals are observed at the top surface of the soil plug. The peak amplitude of the reverse reflected signal at the top of soil plug increases and the peak amplitude of the reflected signal at the pile toe decreases as the spring constant increases. It is also observed that the arrival time of the reflected signal will gradually become shorter, which indicates that the velocity of longitudinal stress waves propagating in the pipe pile would decrease if there is soil plug inside pipe pile. This issue will be discussed in the next section.

Fig. 9 depicts the influence of the damping coefficient of the distributed Voigt model on the pile vertical dynamic response for $k_{2}=0$. It can be observed from Fig. 9 that the amplitude of the resonant peak increases with the increase in the damping coefficient, but the resonant frequency remains almost invariant. 
It can also be noted that the peak amplitude of the reflected signal of pile toe decreases as the damping coefficient increases. It is also noted that the reverse reflected signal at the top of soil plug is negligible for $k_{2}=0$, i.e., the reverse reflected signal at the top of soil plug is mainly governed by the spring constant.

Based on this discussion, it is concluded that: the spring constant of the distributed Voigt model may affect: (1) the amplitude of the resonant peak and the resonant frequency in the velocity admittance curve, (2)the peak amplitudes of the reflected signal at pile toe and top of soil plug; and the damping coefficient may affect: (1) the amplitude of resonant peak in velocity admittance curve, (2) the peak amplitude of reflected signal at the pile toe. Therefore, it seems that the dynamic interaction of soil plug and pipe pile becomes more prominent as the parameter values of the additional mass model increase.

\section{Parametric study and discussion}

A parametric study is conducted to investigate the vertical dynamic response of the pipe pile in terms of its velocity admittance curve and reflected wave signal curve in order to gain further insights into the interaction mechanism between the soil plug and the pipe pile. Unless otherwise stated, the soil profile is considered to comprise of two layers: one layer along the pile shaft and one layer extending from the pile toe to the end of soil profile. The density, shear wave velocity and Poisson's ratio of soil below the pile toe are equal to $2000 \mathrm{~kg} / \mathrm{m}^{3}, 220 \mathrm{~m} / \mathrm{s}$ and 0.35 , respectively. The density and shear wave velocity of soil along the pile shaft are given as $1800 \mathrm{~kg} / \mathrm{m}^{3}$ and $120 \mathrm{~m} / \mathrm{s}$, respectively. According to the analysis results shown in section 'Parameter sensitivity analysis of the additional mass model', the spring constant and damping coefficient of the distributed Voigt model are set to $600 \mathrm{kN} \cdot \mathrm{m}^{-3}$ and $300 \mathrm{kN} \cdot \mathrm{m}^{-3} \cdot \mathrm{s}$, respectively.

\section{Influence of the wall thickness of pipe pile on its vertical dynamic response}

First, the influence of the pile wall thickness on its vertical dynamic response is investigated. The parameters used in the analysis are as follows. The density, shear wave velocity and height of the soil plug are equal to $1800 \mathrm{~kg} / \mathrm{m}^{3}, 120 \mathrm{~m} / \mathrm{s}$ and $5 \mathrm{~m}$, respectively. The length, outer radius, density and longitudinal wave velocity of the pipe pile are equal to $15 \mathrm{~m}, 0.4 \mathrm{~m}, 2500 \mathrm{~kg} / \mathrm{m}^{3}$ and $4000 \mathrm{~m} / \mathrm{s}$, respectively. The wall thickness of the pipe pile is set to $b=0.06,0.08,0.10,0.12$ and $0.14 \mathrm{~m}$ (the pile outer dimeter remains constant, $d=0.8 \mathrm{~m})$.

Fig. 10 illustrates the influence of the pile wall thickness on its vertical dynamic response. Fig. 10a shows that the amplitude of the resonant peak of velocity admittance curve increases as the pile wall thickness increases, but the resonant frequency remains basically unchanged. For a relatively thin pile wall 
(i.e. $b=0.06 \mathrm{~m}$ ), the velocity admittance curve displays a plateau at high frequency with a mean value of 1.0. As indicated in Fig. 10b, both the peak amplitudes of the reflected signal at the pile toe and the reverse reflected signal at the top of the soil plug increase as the wall thickness of pipe pile increases. It is also observed that the reflected signal at the pile toe becomes weaker as the pile wall thickness decreases, which indicates that the effective detection depth (i.e. the maximum depth which can receive distinguishable reflected signal at the corresponding location in the reflected wave signal curve) in low-strain integrity testing of pipe piles decreases as the pile wall thickness decreases.

\section{Influence of the density of the soil plug on the pile vertical dynamic response}

Earlier studies (e.g. Matsumoto and Takei 1991; Gavin and Lehane 2003; Paik and Salgado 2003) showed that the soil plug can have a marked influence on the bearing capacity of pipe pile. However, the influence of the soil plug on the pile vibration characteristics has not been discussed in detail. This section attempts to evaluate the influence of the density of soil plug on the pile vertical dynamic response. The parameters used herein are as follows: the length, outer radius, wall thickness, density and longitudinal wave velocity of the pipe pile are equal to $15 \mathrm{~m}, 0.4 \mathrm{~m}, 0.12 \mathrm{~m}, 2500 \mathrm{~kg} / \mathrm{m}^{3}$ and $4000 \mathrm{~m} / \mathrm{s}$, respectively. The shear wave velocity and height of the soil plug are equal to $120 \mathrm{~m} / \mathrm{s}$ and $5 \mathrm{~m}$, respectively.

Fig. 11 depicts the influence of the density of the soil plug on the vertical dynamic response of pipe pile. The results are presented in terms of $\bar{\rho}$, defined as the ratio of the density of soil plug to the density of the soil along the pile shaft, which indicates looser (softer) soil plug for $\bar{\rho}<1.0$, and denser (stiffer) soil plug for $\bar{\rho}>1.0$. Fig. 11a shows that the amplitude of the resonant peak increases for $\bar{\rho}<1.0$, and decreases for $\bar{\rho}>1.0$. However, the soil plug density has a minor effect on the resonant frequency. Fig. $11 \mathrm{~b}$ shows that the peak amplitude of the reflected signal at the pile toe increases as the soil plug density decreases and decreases as the soil plug becomes denser than the normal soil. In contrast, the peak amplitude of the reflected signal at the top of the soil plug decreases for $\bar{\rho}<1.0$ and increases for $\bar{\rho}>$

1.0. These observations can be explained by utilizing Eq. (19), which shows that $K_{\mathrm{s}, j}$ increases with the increase of soil plug density. The increase in $K_{\mathrm{s}, j}$ result in more prominent dynamic interaction of soil plug and pipe pile, which leads to the increase of the peak amplitude of the reflected signal at the top of soil plug. It is worth noting that the inertia and radiation damping of soil plug increase with the increase of soil plug density, which may result in the decrease of the peak amplitude of the reflected signal at the pile toe. 


\section{Influence of the height of the soil plug on the vertical dynamic response of pipe pile}

When investigating the influence of the height of the soil plug on the vertical dynamic response of pipe pile, the parameters of soil-pile system are set to: The length, outer radius, wall thickness, density and longitudinal wave velocity of the pipe pile are equal to $15 \mathrm{~m}, 0.4 \mathrm{~m}, 0.12 \mathrm{~m}, 2500 \mathrm{~kg} / \mathrm{m}^{3}$ and $4000 \mathrm{~m} / \mathrm{s}$, respectively. The density and shear wave velocity of the soil plug are equal to $1800 \mathrm{~kg} / \mathrm{m}^{3}$ and $120 \mathrm{~m} / \mathrm{s}$, respectively. $\bar{h}$ defines the ratio of the height of soil plug to the length of pipe pile and it is assumed equal to $\bar{h}=0,0.25,0.5,0.75,1.0$, in which $\bar{h}=0$ suggests that there is no soil plug inside pipe pile and $\bar{h}=1.0$ indicates that the soil plug fills the entire cylindrical hole of the pipe pile.

Fig. 12 illustrates the influence of the height of the soil plug on the vertical dynamic response of pipe pile. As shown in Fig. 12a, for $\bar{h}=0$ the velocity admittance curve at the high frequency range displays oscillatory form with uniform resonant peak. As the height of the soil plug increases, the oscillatory part of the velocity admittance curve displays increasingly complex characteristics of non-uniform peaks with irregular distribution. For $\bar{h}=1.0$, the oscillations of the velocity admittance curve segment (at high frequency) diminish and the curve tends to a plateau. Fig. $12 \mathrm{~b}$ shows that the reflected wave exhibits the typical characteristics of intact pipe pile with no reflected wave signal between pile head and pile toe when $\bar{h}=0$. As the soil plug height increases, a reverse reflected signal occurs between the head wave and the reflected signal at the pile toe; and the reverse reflected signal moves close to the head wave as the height of the soil plug increases. Meanwhile, the peak amplitude of the reflected signal at the pile toe decreases significantly as the height of the soil plug increases. It is also noted that the arrival time of peak of the pile toe reflected signal is delayed as the height of the soil plug increases. Excluding the possibility that the delay of the pile toe reflected signal is caused by multiple reflections of the signal reflected at the top of soil plug, it is likely that this delay is due to a decrease in the velocity of longitudinal stress waves propagating in the pipe pile induced by the height of soil plug. Therefore, it is necessary to conduct a set of validation against experimental results to explain these analytical results.

\section{Validation against experimental results}

\section{Testing methodology}

To validate the observations made on the results of the additional mass model, a series of confirmatory 
tests on a model pipe pile were performed immediately following low-strain integrity tests. The main purposes of these tests are to: (1) Verify the occurrence of reverse reflected signal at the top of soil plug; (2) Confirm that the velocity of longitudinal stress waves propagating in the pipe pile is affected by the height of soil plug.

Test materials and instruments: (1) the model pipe pile was a polypropylene-random (PP-R) pipe of length $2.6 \mathrm{~m}$ as shown in Fig. 13a. The outer diameter, wall thickness and density calibrated by factory of this model pipe pile were $110 \mathrm{~mm}, 10 \mathrm{~mm}$ and $900 \mathrm{~kg} / \mathrm{m}^{3}$, respectively. (2) the soil plug was simulated using fine sand. The density of soil plug was controlled to be $1800 \mathrm{~kg} / \mathrm{m}^{3}$. (3) The EPPDS Pile Dynamic Testing System for low-strain integrity testing, shown in Fig. 13b, which was developed by Zhejiang University, was used to monitor wave propagation in pile during testing. The host computer of EPPDS is Pierre Cardin PC729 with 1.2GMHz main frequency and the charge amplifier is integrated in the host computer. The resolution of the data acquisition system is 16bits, and the range of sampling frequency can be programmed with $0-100 \mathrm{kHz}$. A piezoelectric accelerometer is used to measure the acceleration of the pile head.

To investigate the vibration characteristics of model pipe pile for different engineering conditions, the height of soil plug inside the model pipe pile were set to: $H_{\mathrm{s}}=0,0.5,1.0,1.5,2.0$ and $2.6 \mathrm{~m}$, as indicated in Fig. 14. To ensure that the soil plug inside the model pipe pile was homogeneous, the fine sand was poured into the PP-R Pipe and compacted in $150 \mathrm{~mm}$ layers using the same compaction effort.

\section{Test results and discussion}

The analysis of the model test results proceeds as follows:

Step 1: The longitudinal wave velocity $\left(V_{\mathrm{p}}\right)$ of the pipe material is initially assumed (say $1200 \mathrm{~m} / \mathrm{s}$ ) and the wave signal curve of the model pipe pile is analyzed (i.e. calculating the arrival time of the peak of the reflected signal at the pile toe) and is compared with the measured signal for the case of soil plug height $H_{\mathrm{s}}$ $=0 \mathrm{~m}$ (Fig. 15a). If no match is achieved, $V_{\mathrm{p}}$ is varied and the calculated signal is compared with the measured one until good match is achieved. The value of $V_{\mathrm{p}}$ that resulted in the best match, herein $1400 \mathrm{~m} / \mathrm{s}$, is considered representative of the pipe pile material. The material damping coefficient of the model pipe pile and the dimensionless pulse width of the exciting force are then obtained by comparing the peak amplitudes of the reflected signal at the pile toe in the calculated and measured reflected wave signal curves. These were found to be $29.484 \mathrm{kN} \cdot \mathrm{m}^{-3} \cdot \mathrm{s}$ and $\bar{T}_{0}=0.37$. 
Step 2: The reflected wave signal curve of the model pipe pile is calculated for the case of $H_{\mathrm{s}}=0.5 \mathrm{~m}$ (i.e. calculating the time difference between the reverse reflected signal at the top of soil plug and the reflected signal at the pile toe, and analyzing the peak amplitudes of these reflected signals) considering initial values for the Voight model parameters. The obtained curve is compared with the measured one as indicated in Fig. 15b. The values of the spring constant and damping coefficient are then varied and the analysis is repeated until good match between calculated and measured signals is achieved. The values of the spring constant and damping coefficient that resulted in best match are $785 \mathrm{kN} \cdot \mathrm{m}^{-3}$ and $153 \mathrm{kN} \cdot \mathrm{m}^{-3} \cdot \mathrm{s}$

Step 3: Utilizing the parameters obtained in steps 1 and 2, the reflected wave signal curves of the model pipe pile with soil plug of height $H_{\mathrm{s}}=1.0 \mathrm{~m}, 1.5 \mathrm{~m}, 2.0 \mathrm{~m}$ and $2.6 \mathrm{~m}$ are calculated and compared with the measured curves and the results are presented in Fig. 15c, Fig. 15d, Fig. 15e and Fig. 15f, respectively.

Step 4: The composite velocity of the whole model pipe pile is calculated based on the arrival times of the peak points of the head wave and the reflected signal at the pile toe, and the obtained results are shown in Table 1.

Step 5: The composite velocity of the pipe pile segment filled with soil plug is calculated considering the arrival times of the peak points of the reverse reflected signal at the soil plug top and the reflected signal at the pile toe. The calculated results are also given in Table 1.

As indicated in Fig. 15, the trends of the calculated time histories of all six cases are in good agreement with the measured time histories. It is also evident from Fig. 15 that the arrival time of the peak of the reflected signal at the pile toe increases as the height of soil plug increases. In addition, Table 1 shows that the calculated and measured composite velocity values for the whole model pipe pile and for the pipe pile segment with soil plug agree well. It is also noted that the composite velocity of the pipe pile segment with soil plug decreases with the increase of soil plug height.

The good agreement between the calculated and measured responses confirms that the additional mass model can simulate the dynamic interaction between the soil plug and the pipe pile. The results confirm that the reflected wave signal curve displays a reverse reflected signal at the top of soil plug. Finally, the results show that the test velocity of pipe pile decreases due to soil plug, and that the test velocity decreases further as the height of soil plug increases.

Based on the above observations and discussion, the concept of Apparent Wave Velocity of Pipe Pile 
(AWVPP) is proposed. This concept can help interpret the results of integrity tests on pile foundations. The $\operatorname{AWVPP}\left(V_{\mathrm{a}}\right)$ is defined as the actual pile length divided by the difference between arrival times of the peak of the reflected wave at the pile toe and the peak of the head wave. The proposed analysis demonstrates that the $V_{\mathrm{a}}$ is not equal to the longitudinal wave velocity of pipe material due to the interaction of the pipe pile with the soil plug and its surrounding soil.

In interpreting the results of integrity tests on pipe piles, it is common to estimate the longitudinal wave velocity of pile material by the inversion method, which is set as the initial testing velocity (i.e. the velocity input onto the test instrument before tests) of pipe pile. However, this may lead to errors in assessing the pile length and position of pile defect, and $V_{\mathrm{a}}$ should be used as the pile test velocity. Therefore, in order to improve the interpretation of integrity tests on pipe piles, it is proposed to utilize the AWVPP concept according to the following procedure.

Define $V_{\mathrm{p}}, V_{\mathrm{a}}$ and $V_{\mathrm{c}}$ as the longitudinal wave velocity of pipe pile material, AWVPP and the composite velocity of the pipe pile segment with soil plug, respectively. These velocities can be related in terms of the pipe pile length and soil plug height as:

$$
\frac{H-H_{\mathrm{s}}}{V_{\mathrm{p}}}+\frac{H_{\mathrm{s}}}{V_{\mathrm{c}}}=\frac{H}{V_{\mathrm{a}}}
$$

where, $H, H_{\mathrm{s}}, V_{\mathrm{p}}$ and $V_{\mathrm{a}}$ can be obtained by field measurements or the inversion method. The pile composite velocity $\left(V_{\mathrm{c}}\right)$ considering the effect of soil plug can be calculated employing Eq. (32). With the accurate $V_{\mathrm{c}}$, we can establish the quantitative relationship among the design parameters of pipe pile, the height of soil plug and the composite velocity $V_{\mathrm{c}}$. Then, the empirical formulas for the spring constant $k_{j}$ and damping coefficient $\eta_{j}$ of the distributed Voigt model and the empirical formula for the Apparent Wave Velocity of Pipe Pile can also be obtained through repeated back analysis with the accurate $V_{\mathrm{c}}$.

The influence of the properties of the soil plug and of the interface characteristics of soil plug and pipe pile on the pile composite velocity can be investigated theoretically via the proposed analysis. Consequently, a relationship between $V_{\mathrm{a}}$ and the properties of the soil plug can be obtained through numerical modeling or field tests, which can provide a more reliable interpretation of pile integrity tests.

\section{Conclusions}

The additional mass model is proposed to account for the soil plug effect and to explain the observed 
behavior of pipe piles during low-strain integrity tests. Based on the additional mass model, analytical solutions are derived for the analysis of the dynamic response of pipe piles in the frequency domain and the corresponding quasi-analytical solution in the time domain. The pipe pile is assumed to be subjected to a vertical semi-sinusoidal exciting force at its head and the solution is derived by means of integral transform and transfer function techniques. A parameter sensitivity analysis was conducted to obtain the approximate ranges of the parameters of the distributed Voigt model representing the soil plug in the additional mass model. In addition, integrity tests were conducted on pipe pile models in order to evaluate the validity of the developed numerical solution. Based on the results of the parametric study and the comparison against the experimental results, the following conclusions are drawn:

(1) The effective detection depth of the low-strain integrity testing of pipe pile decreases as the pile wall thickness increases.

(2) There is an obvious reverse reflected signal at the top of soil plug in reflected wave signal curve; this signal moves closer to the head wave as the soil plug height increases.

(3) The velocity of longitudinal stress waves propagating in the pipe pile decreases as the height of soil plug increases.

(4) The amplitude of resonant peak in velocity admittance curve and the peak amplitude of the reflected signal at the pile toe decrease as the density of soil plug increases; however, the peak amplitude of the reflected signal at the top of the soil plug increases as the density of soil plug increases.

(5) The theoretical solution developed herein is verified through a set of model tests. On the basis of the model test results, the concept of Apparent Wave Velocity of Pipe Pile (AWVPP) is also introduced.

\section{Acknowledgements}

This research is supported by the National Natural Science Foundation of China (Grant No. 51309207, 51678547), the China Postdoctoral Science Foundation Funded Project (Grant No. 2016M600711 and No. 2013T60759). The Research Funds provided by MOE Engineering Research Center of Rock-Soil Drilling \& Excavation and Protection (Grant No. 201402), and the Fundamental Research Funds for the Central Universities-Cradle Plan for 2015 (Grant No. CUGL150411) are also acknowledged. 


\section{References}

Chen, F., and Luo, W. Z. 2004. Dimension effect on low strain integrity testing of prestressed pipe piles. Chinese Journal of Geotechnical Engineering, 26(3): 353-356. [In Chinese.]

Ding, X. M., Liu, H. L., Liu, J. Y., and Chen, Y. M. 2011. Wave propagation in pipe pile for low-strain integrity testing. Journal of Engineering Mechanics, 137(9): 598-609. doi: 10.1061/(ASCE)EM.1943-7889.0000263.

El Naggar, M. H. and Novak, M. 1994. Non-linear axial interaction in pile dynamics. Journal of Geotechnical Engineering, ASCE, 120(4): 678-696. doi: http://dx.doi.org/10.1061/(ASCE)0733-9410(1994)120:4(678).

Fei, K., Liu, H. L., and Zhang, T. 2007. Three-dimensional effects in low strain integrity test of PCC pile[J]. Rock and Soil Mechanics, 28(6): 1095-1102. [In Chinese.]

Gavin, K. G., and Lehane, B. M. 2003. The shaft capacity of pipe piles in sand. Canadian Geotechnical Journal, 40(1): 36-45. doi: 10.1139/T02-093.

Huang, D. Z., and Chen, L. Z. 2005. 3D finite element analysis of reflected waves in concrete pipe pile with defects. Rock and Soil Mechanics, 26(5): 803-808. [In Chinese.]

Ko, J., and Jeong, S. 2015. Plugging effect of open-ended piles in sandy soil. Canadian Geotechnical Journal, 52(5): 535-547. doi: 10.1139/cgj-2014-0041.

Kraft, L. M., Focht, J. A., and Amerasinghe, S. F. 1981. Friction capacity of piles driven into clay. Journal of Geotechnical Engineering, ASCE, 107(11): 1521-1541.

Liu, H. L., Zheng, C. J., Ding, X. M., and Qin, H. Y. 2014. Vertical dynamic response of a pipe pile in saturated soil layer. Computers and Geotechnics, 61: 57-66. doi: 10.1016/j.compgeo.2014.04.006.

Liu, R., Zhou, R. H., and Yan, S. H. 2005. Plug effect on drivability of large-diameter steel piles. Ocean Engineering, 23(2): 71-76. [In Chinese.]

Liyanapathirana, D. S., Deeks, A. J., and Randolph, M. F. 2001. Numerical modelling of the driving response of thin-walled open-ended piles. International Journal for Numerical and Analytical Methods 
in Geomechanics, 25(9): 933-953. doi: 10.1002/nag.161.

Lu, Z. T., Wang, Z. L., and Liu, D. J. 2013. Study on low-strain integrity testing of pipe-pile using the elastodynamic finite integration technique. International Journal for Numerical and Analytical Methods in Geomechanics, 37(5): 536-550. doi: 10.1002/nag.2122.

Lysmer, J., and Richart, F. E. 1966. Dynamic response of footing to vertical load. Soil Mechanical and Foundation Division, ASCE, 2(1): 65-91.

Matsumoto, T., and Takei, M. 1991. Effects of soil plug on behaviour of driven pipe piles. Soils and Foundations, 31(2): 14-34. doi: 10.3208/sandf1972.31.2_14.

Novak, M. 1974. Dynamic stiffness and damping of piles. Canadian Geotechnical Journal, 11(4): 574-598.

Paik, K., Salgado, R. 2003. Determination of bearing capacity of open-ended piles in sands. Journal of Geotechnical and Geoenvironmental Engineering, ASCE, 129(1): 46-57. doi: 10.1061/(ASCE)1092-0241(2003)129:1(46).

Randolph, M. F., and Simons, H. A. 1986. An improved soil model for one dimensional pile driving analysis. Proceeding of 3rd International Conference on Numerical Methods in Offshore Piling, Nantes, 1-17.

Sakr, M., El Naggar, M. H., and Nehdi, M. 2004. Novel toe driving for thin-walled piles and performance of fiberglass-reinforced polymer (FRP) pile segments. Canadian Geotechnical Journal, 41(2): 313-325. doi: 10.1139/T03-089.

Wang, K. H., Wu, W. B., Zhang, Z. Q., and Leo, C. J. 2010. Vertical dynamic response of an inhomogeneous viscoelastic pile. Computers and Geotechnics, 37(4): 536-544. doi: 10.1016/j.compgeo.2010.03.001.

Wu, W. B. 2012. Vertical vibration theory of pile-soil system based on fictitious soil pile method and its application. Ph.D. thesis, Zhejiang University, Hangzhou, China. [In Chinese.]

Wu, W. B., Jiang, G. S., Huang, S. G., and Leo, C. J. 2014. Vertical dynamic response of pile embedded in layered transversely isotropic soil. Mathematical Problems in Engineering, vol. 2014, Article ID 
126916, 12 pages. doi: 10.1155/2014/126916.

Wu, W. B., Liu, H., El Naggar, M. H., Mei, G. X., and Jiang, G. S. 2016. Torsional dynamic response of a pile embedded in layered soil based on the fictitious soil pile model. Computers and Geotechnics, 80: 190-198. doi: 10.1016/j.compgeo.2016.06.013.

Yan, S. W., Dong, W., Liu, R., Yin, H. J., and Fan, Z. X. 2009. Study of influence of soil plug on driving piles of offshore oil drilling platform. Chinese Journal of Rock Mechanics and Engineering, 28(4): 703-709. [In Chinese.]

Zheng, C. J., Liu, H. L., Kouretzis, G. P., Sloan, S. W., Ding, X. M. 2015. Vertical response of a thin-walled pipe pile embedded in viscoelastic soil to a transient point load with application to low-strain integrity testing. Computers and Geotechnics, 70: 50-59. doi: 10.1016/j.compgeo.2015.07.016.

Zheng, C. J., Liu, H. L., Ding, X. M., Kouretzis, G. P., Sheng, D. C. 2016. Three-dimensional effects in low-strain integrity testing of large diameter pipe piles. Journal of Engineering Mechanics, 142(9). doi: 10.1061/(ASCE)EM.1943-7889.0001117.

List of symbols

$\begin{array}{ll}A_{1} & \text { total cross-section coverage area of pipe pile } \\ A_{2} & \text { cross-section area of the } j \text { th pipe pile segment } \\ b & \text { wall thickness of pipe pile } \\ D_{j} & \text { material damping of the } j \text { th soil layer } \\ E_{\mathrm{p}, j} & \quad \text { elastic modulus of the } j \text { th pipe pile segment } \\ f_{j} & \text { frictional force of the } j \text { th surrounding soil layer acting on the outer surface of the } j \text { th pipe } \\ & \quad \text { shear modulus of the } j \text { th soil layer } \\ G_{j} & \text { shear modulus of soil at pile toe } \\ G_{\mathrm{b}} & \text { depth of the } j \text { th layer }\end{array}$




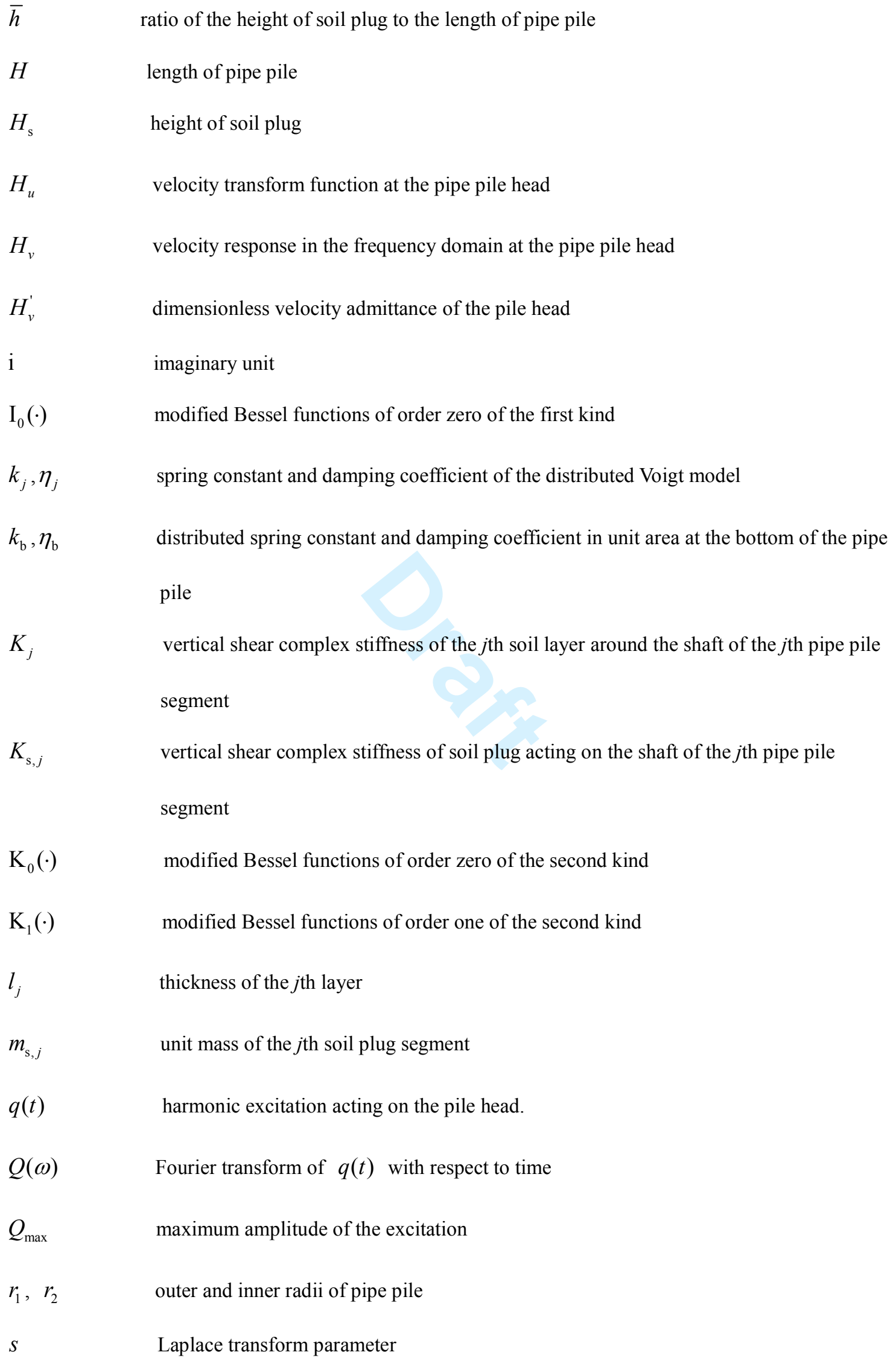


$t_{j}$

$u_{\mathrm{s}, j}(z, t)$

$u_{\mathrm{p}, j}(z, t)$

$U_{\mathrm{s}, j}(z, s)$

$U_{\mathrm{p}, j}(z, s)$

$v_{j}$

$V_{\mathrm{p}, j}$

$V_{\mathrm{b}}$

$V(t)$

$V_{v}^{\prime}$

$V_{\mathrm{a}}$

$V_{\mathrm{c}}$

$W_{j}(r)$

$Z_{\mathrm{p}, j}$

$\rho_{\mathrm{b}}$

$\rho_{j}$

$\rho_{\mathrm{p}, j}$

$\bar{\rho}$ propagation time of elastic longitudinal wave in the $j$ th pipe pile segment

dimensionless propagation time of elastic longitudinal wave in the $j$ th pipe pile segment

dimensionless time variable

whole propagation time of elastic longitudinal wave in the pipe pile

impulse width of the excitation

dimensionless pulse width of the excitation

vertical displacement of the $j$ th soil plug layer

vertical displacement of the $j$ th pipe pile segment

Laplace transform with respect to time of $u_{\mathrm{s}, j}(z, t)$

Laplace transform with respect to time of $u_{\mathrm{p}, j}(z, t)$

shear wave velocity of the $j$ th soil layer

longitudinal wave velocity of the $j$ th pipe pile segment

shear wave velocity of soil at pile toe

velocity response in the time domain at the pipe pile head

dimensionless velocity response in the time domain at the pipe pile head

Apparent Wave Velocity of Pipe Pile

composite velocity of the pipe pile segment filled with soil plug

vertical displacement of the $j$ th soil layer

displacement impedance function at the top of the $j$ th pipe pile segment

mass density of pile end soil

mass density of the $j$ th soil layer

density of the $j$ th pipe pile segment

ratio of the density of soil plug to the density of pile surrounding soil 


$\begin{array}{ll}\tau_{j}(r) & \text { vertical shear stress amplitude at any point in the } j \text { th the soil layer } \\ \delta_{\mathrm{p}, j} & \text { material damping coefficient of the } j \text { th pipe pile segment } \\ \bar{\delta}_{\mathrm{p}, j} & \text { dimensionless material damping coefficient of the } j \text { th pipe pile segment } \\ v_{\mathrm{b}} & \text { Poisson's ratio of pile end soil } \\ \omega & \text { angular frequency } \\ \bar{\omega} & \text { dimensionless angular frequency }\end{array}$




\section{List of figure captions}

Fig. 1 Dynamic interaction model of soil-pile system

Fig. 2 Parameter sensitivity analysis of the distributed Voigt model for $s=1$

Fig. 3 Parameter sensitivity analysis of the distributed Voigt model for $s=5$

Fig. 4 Parameter sensitivity analysis of the distributed Voigt model for $s=10$

Fig. 5 Parameter sensitivity analysis of the distributed Voigt model for $s=1$

Fig. 6 Parameter sensitivity analysis of the distributed Voigt model for $s=5$

Fig. 7 Parameter sensitivity analysis of the distributed Voigt model for $s=10$

Fig. 8 Influence of the spring constant of the distributed Voigt model on the vertical dynamic response of the pipe pile

Fig. 9 Influence of the damping coefficient of the distributed Voigt model on the vertical dynamic response of the pipe pile

Fig. 10 Influence of the pile wall thickness on its vertical dynamic response

Fig. 11 Influence of the density of soil plug on the vertical dynamic response of the pipe pile

Fig. 12 Influence of the height of soil plug on the vertical dynamic response of the pipe pile

Fig. 13 Test materials and apparatus

Fig. 14 Schematic diagram of the model test

Fig. 15 Comparison of calculated and measured reflected wave signal curves of model pipe pile 


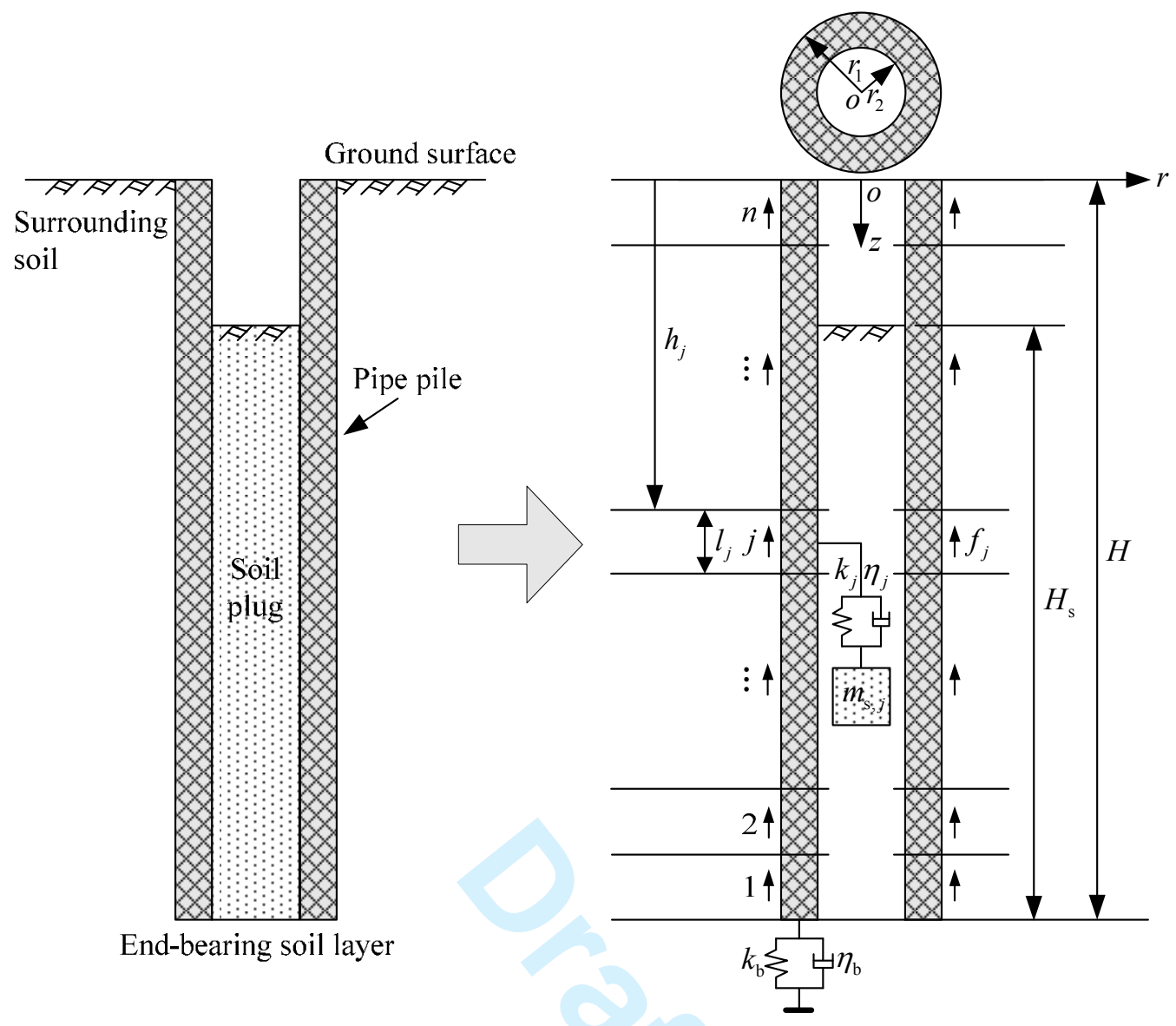

Fig. 1 Dynamic interaction model of soil-pile system 


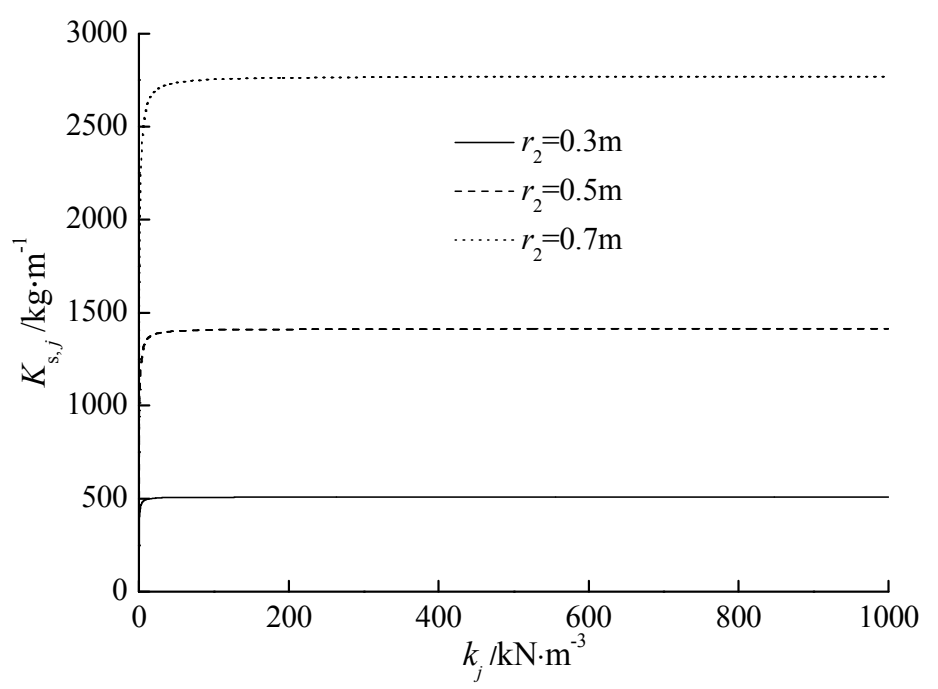

(a) $k_{j}-K_{\mathrm{s}, j}$ curves

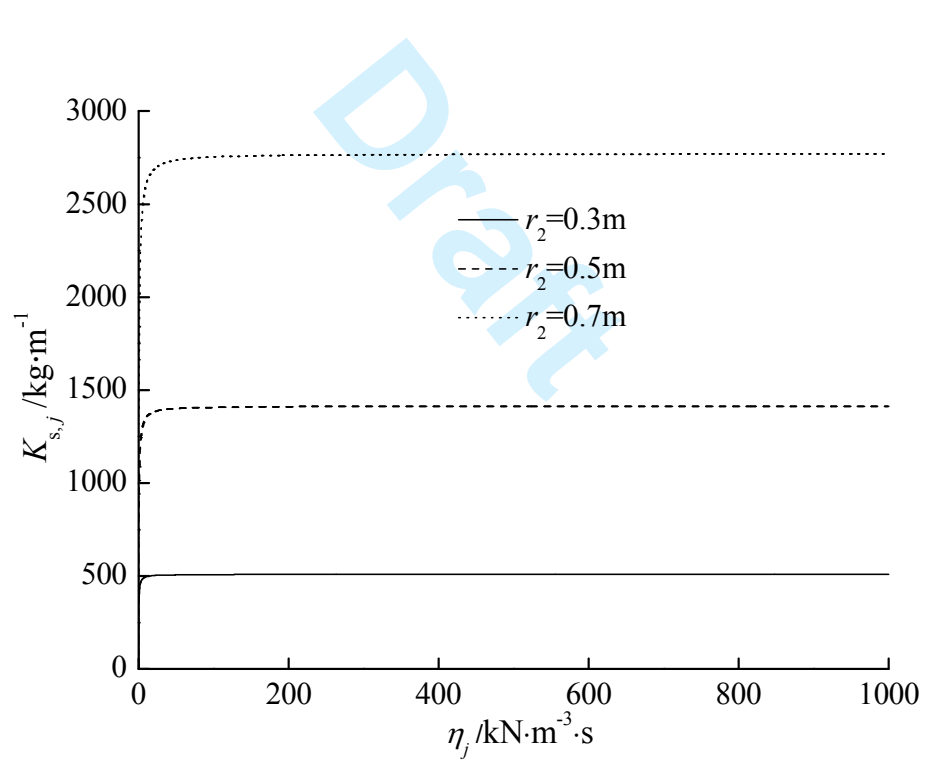

(b) $\eta_{j}-K_{\mathrm{s}, j}$ curves

Fig. 2 Parameter sensitivity analysis of the distributed Voigt model for $s=1$ 


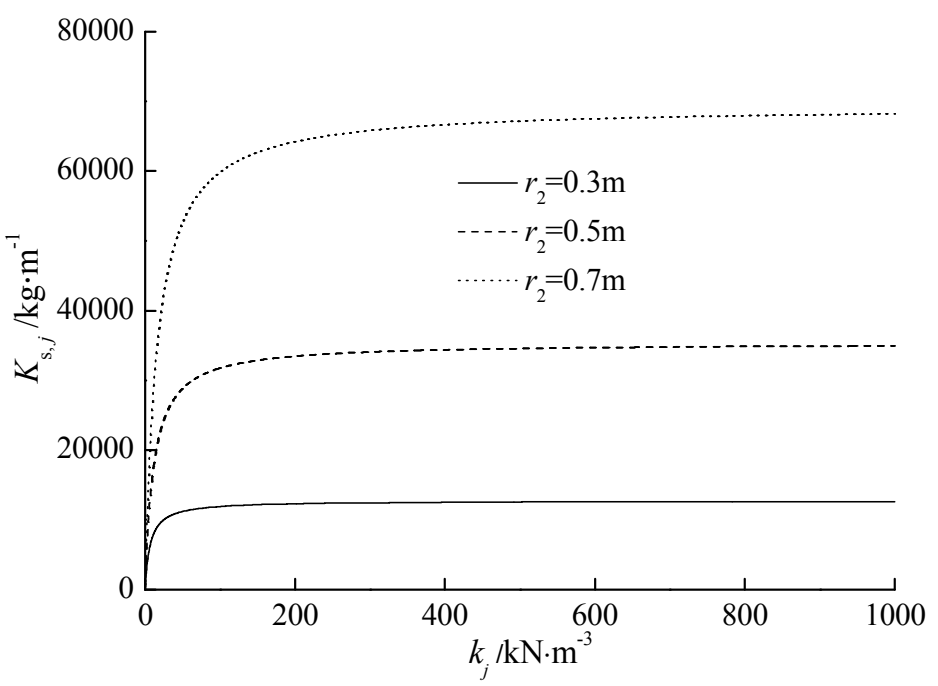

(a) $k_{j}-K_{\mathrm{s}, j}$ curves

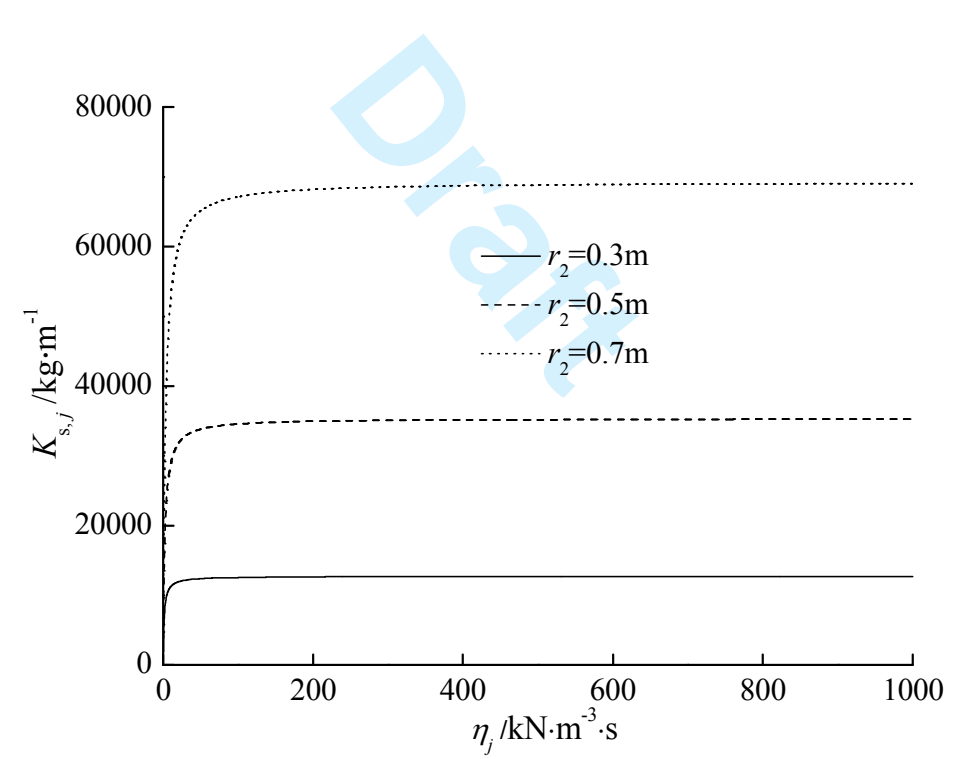

(b) $\eta_{j}-K_{\mathrm{s}, j}$ curves

Fig. 3 Parameter sensitivity analysis of the distributed Voigt model for $s=5$ 


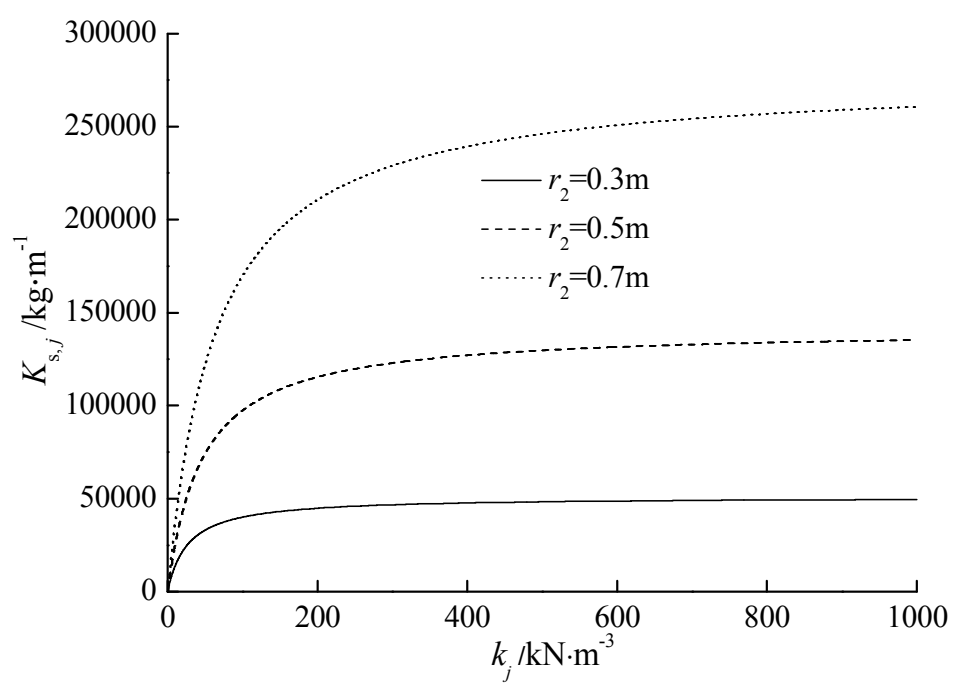

(a) $k_{j}-K_{\mathrm{s}, j}$ curves

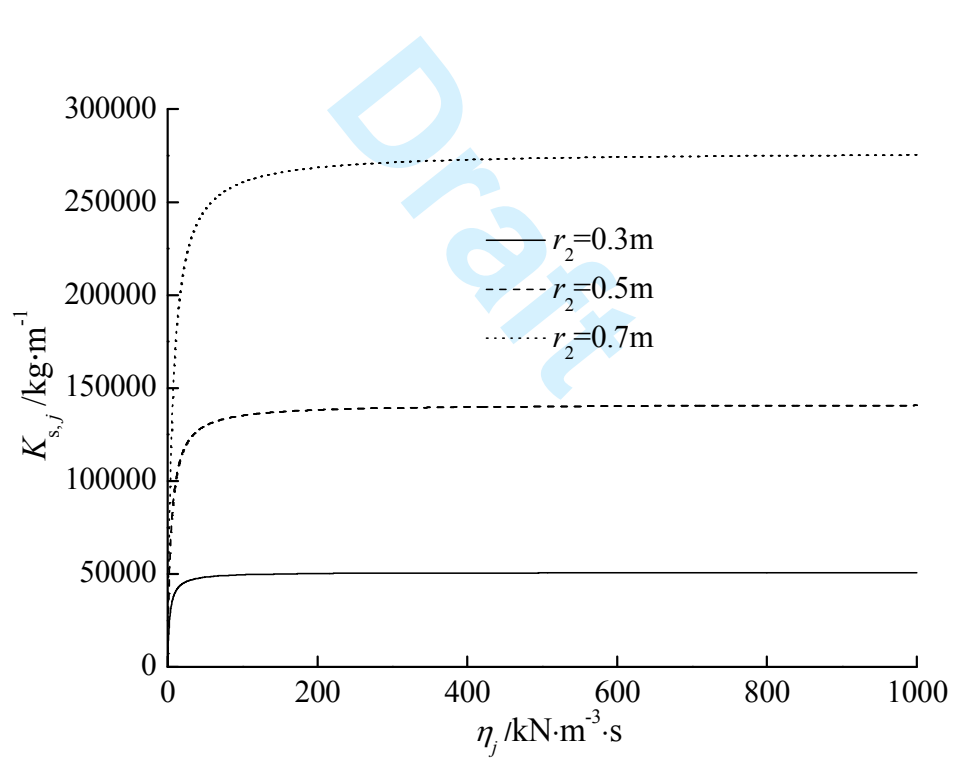

(b) $\eta_{j}-K_{\mathrm{s}, j}$ curves

Fig. 4 Parameter sensitivity analysis of the distributed Voigt model for $s=10$ 


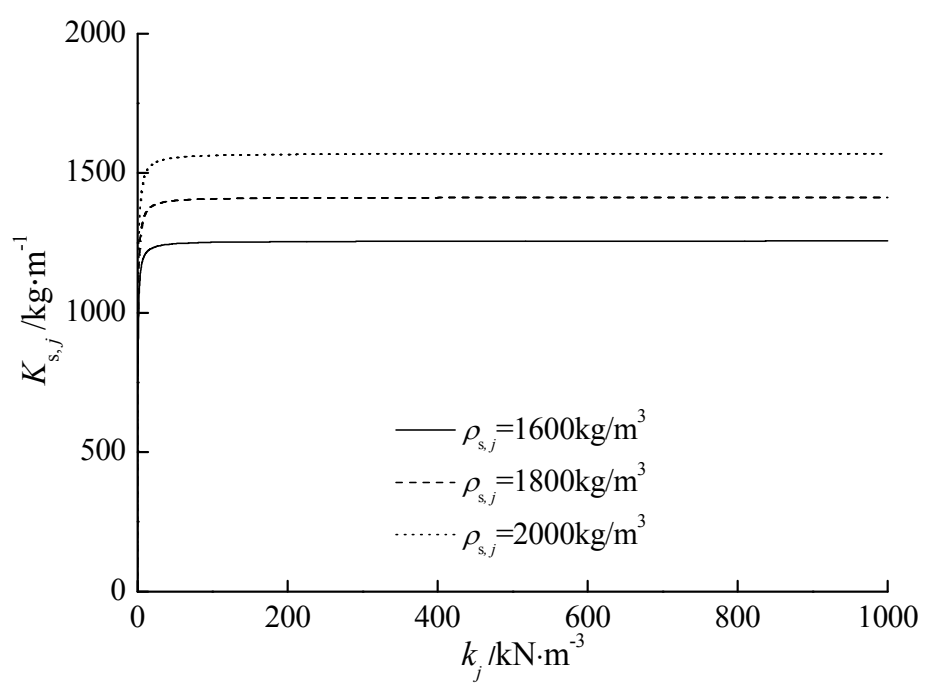

(a) $k_{j}-K_{\mathrm{s}, j}$ curves

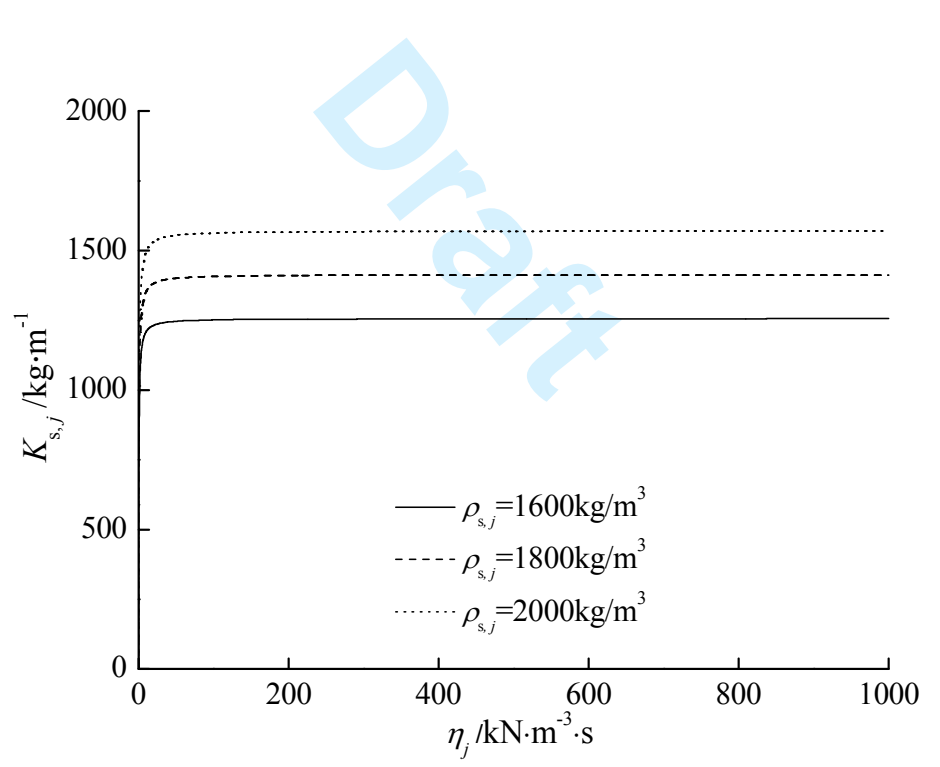

(b) $\eta_{j}-K_{\mathrm{s}, j}$ curves

Fig. 5 Parameter sensitivity analysis of the distributed Voigt model for $s=1$ 


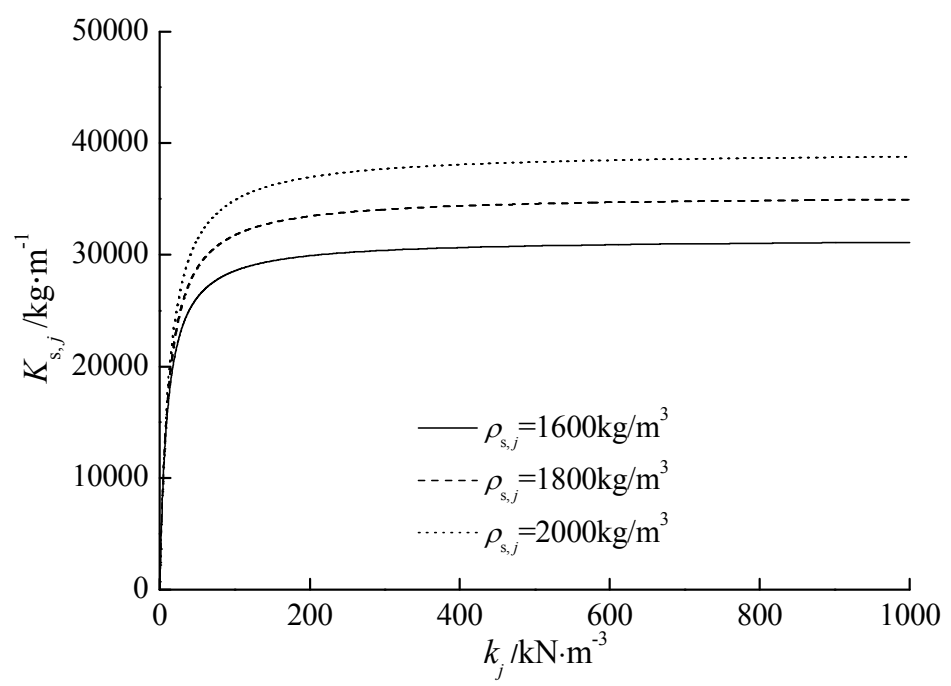

(a) $k_{j}-K_{\mathrm{s}, j}$ curves

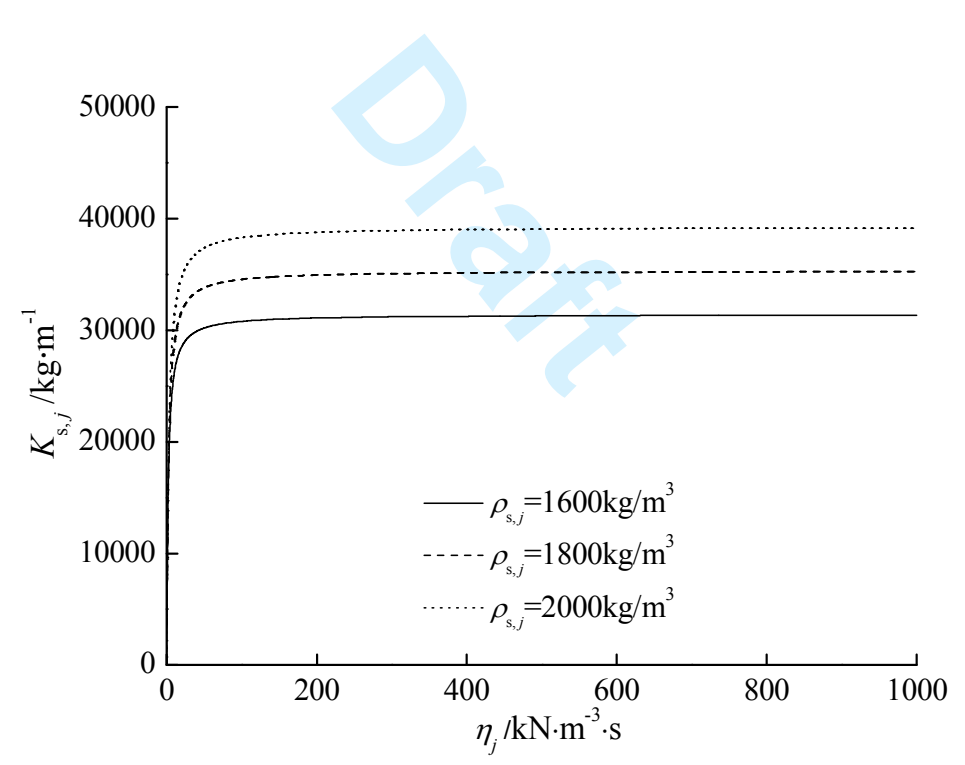

(b) $\eta_{j}-K_{\mathrm{s}, j}$ curves

Fig. 6 Parameter sensitivity analysis of the distributed Voigt model for $s=5$ 


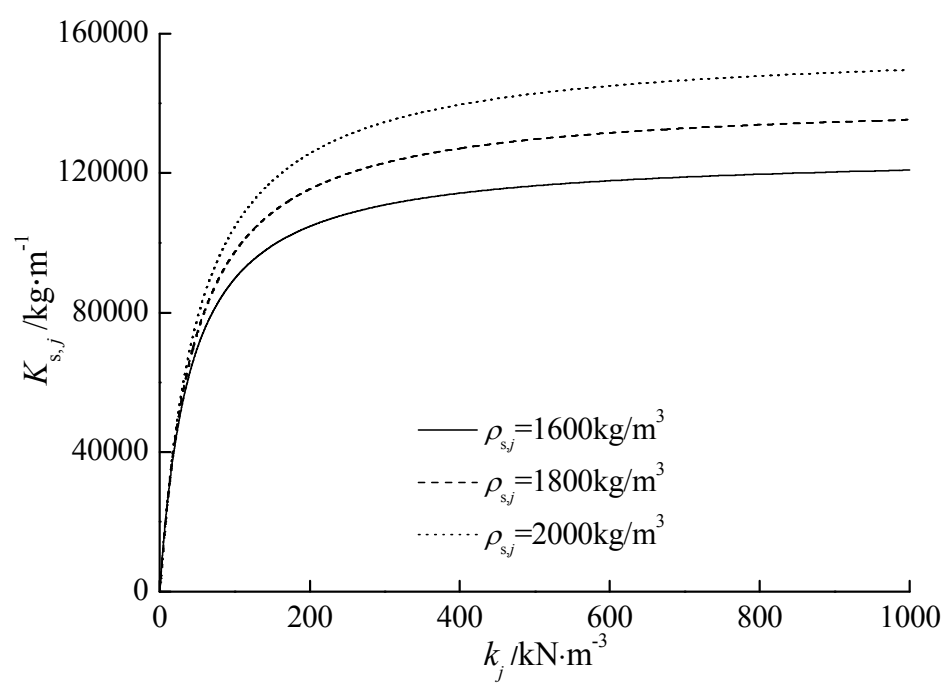

(a) $k_{j}-K_{\mathrm{s}, j}$ curves

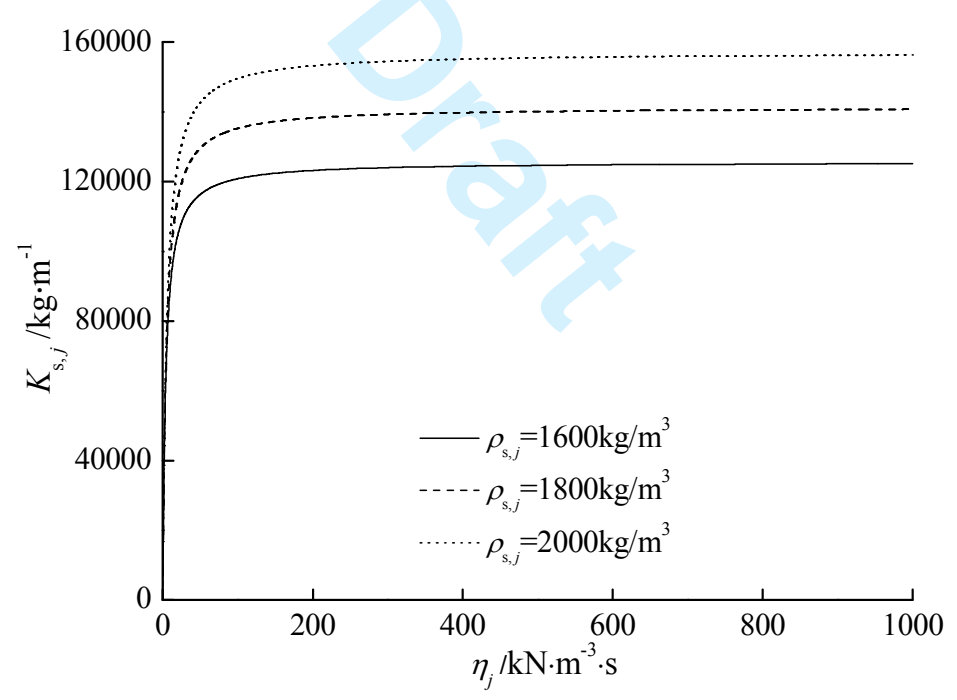

(b) $\eta_{j}-K_{\mathrm{s}, j}$ curves

Fig. 7 Parameter sensitivity analysis of the distributed Voigt model for $s=10$ 


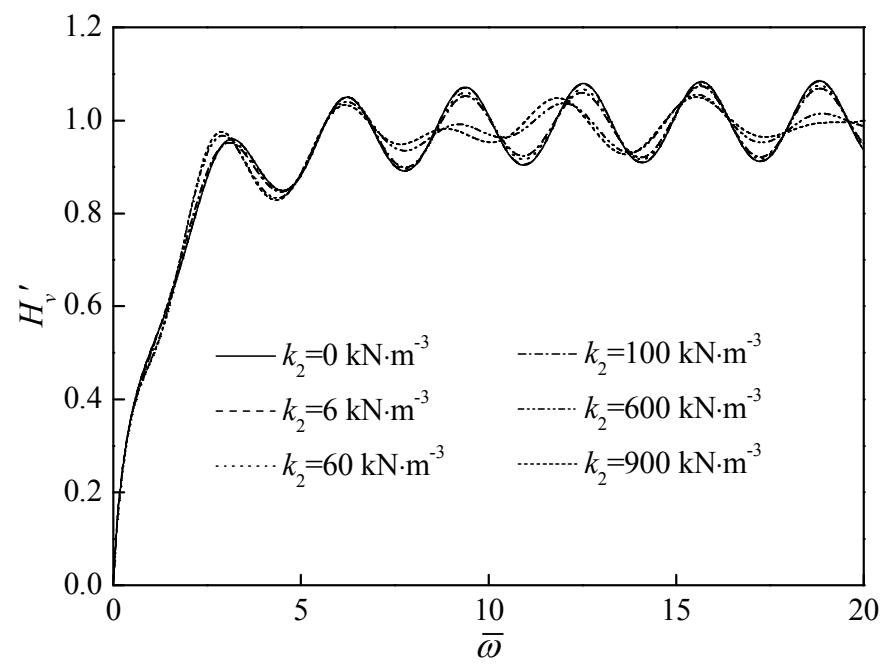

(a) Velocity admittance curves

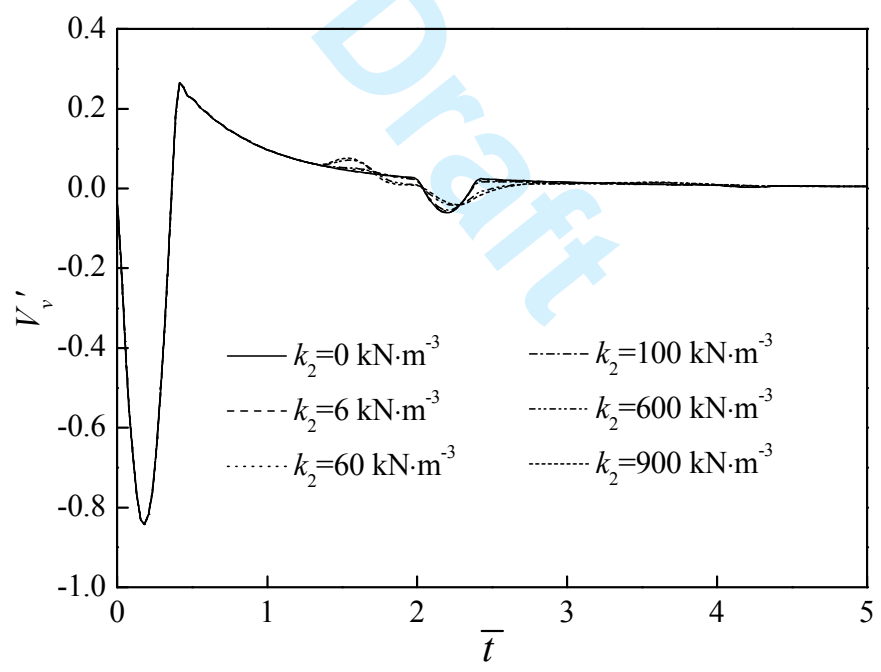

(b) Reflected wave signal curves

Fig. 8 Influence of the spring constant of the distributed Voigt model on the vertical dynamic response of the pipe pile 


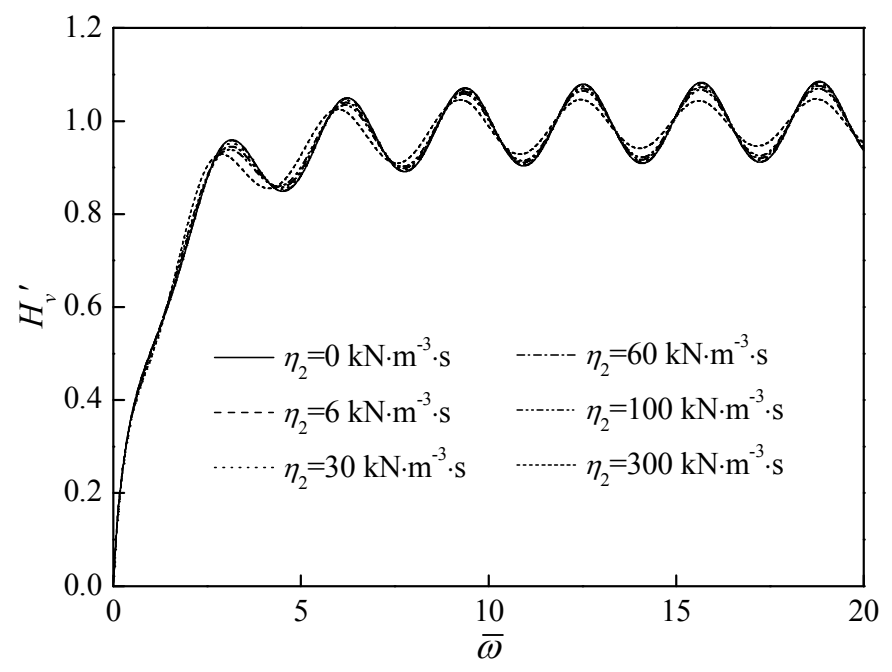

(a) Velocity admittance curves

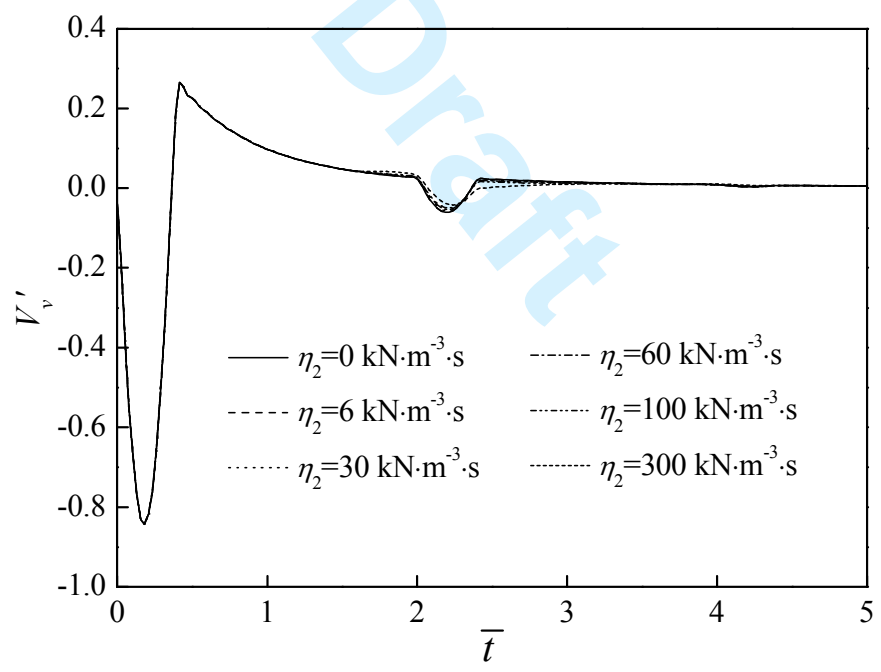

(b) Reflected wave signal curves

Fig. 9 Influence of the damping coefficient of the distributed Voigt model on the vertical dynamic response of the pipe pile 


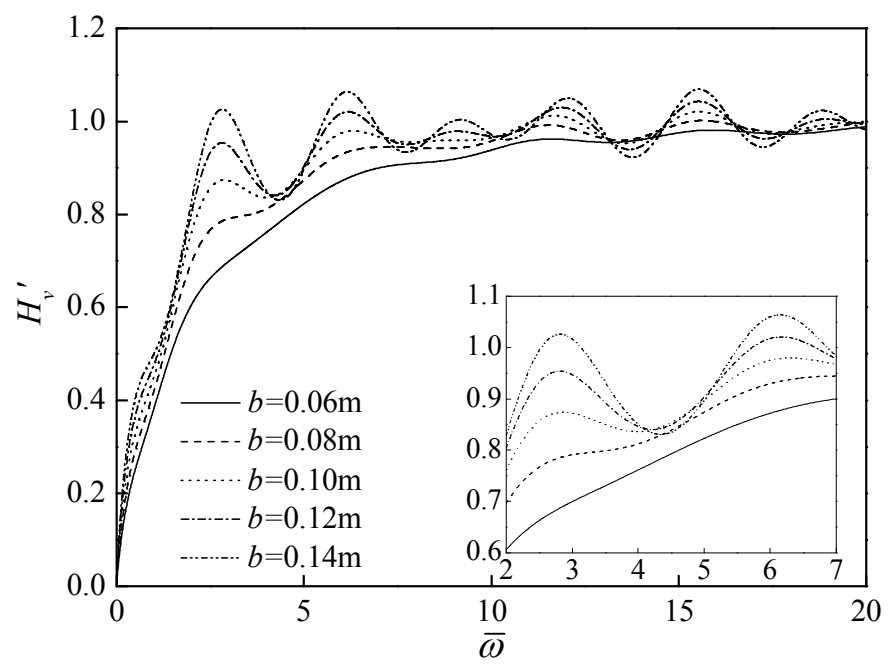

(a) Velocity admittance curves

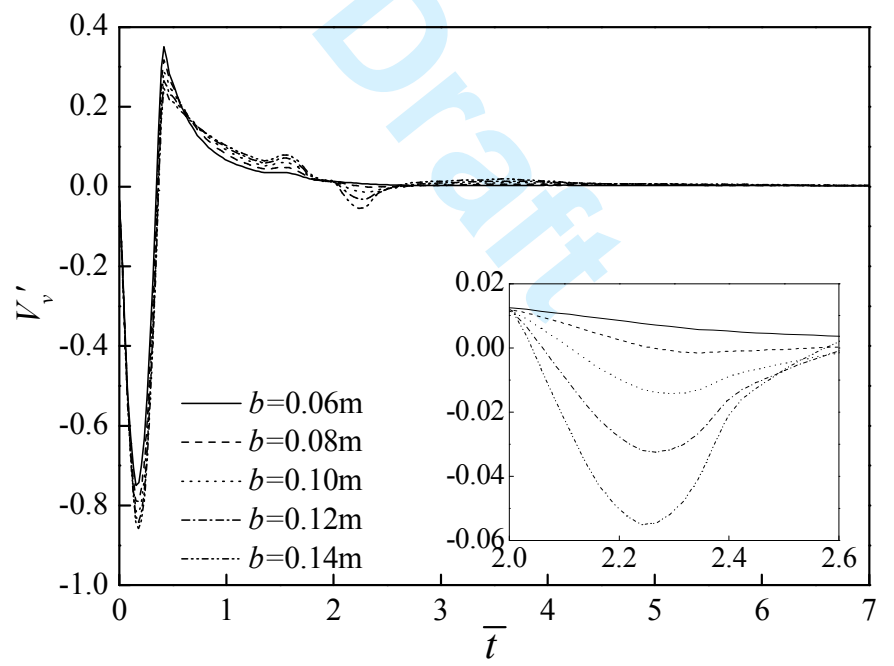

(b) Reflected wave signal curves

Fig. 10 Influence of the pile wall thickness on its vertical dynamic response 


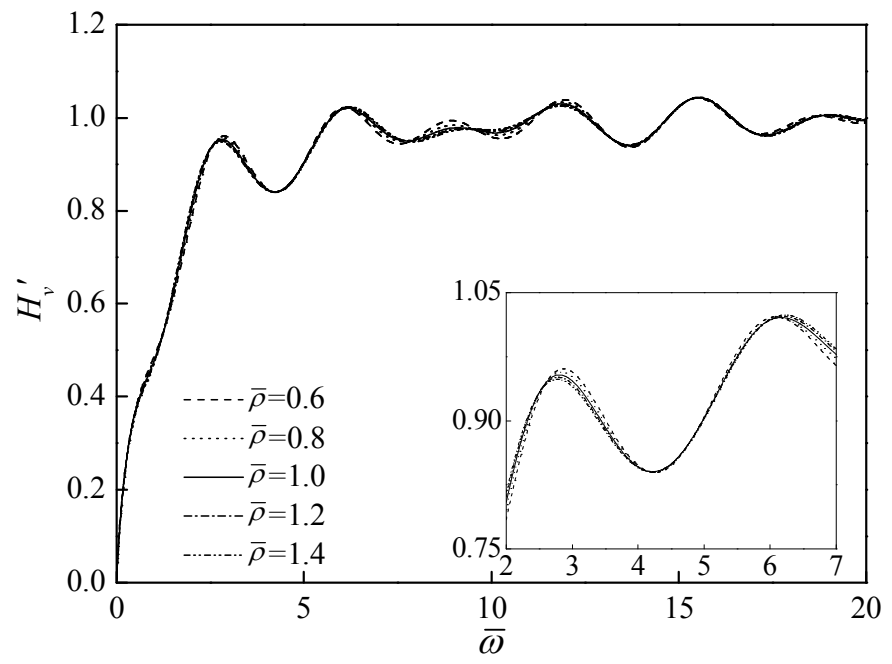

(a) Velocity admittance curves

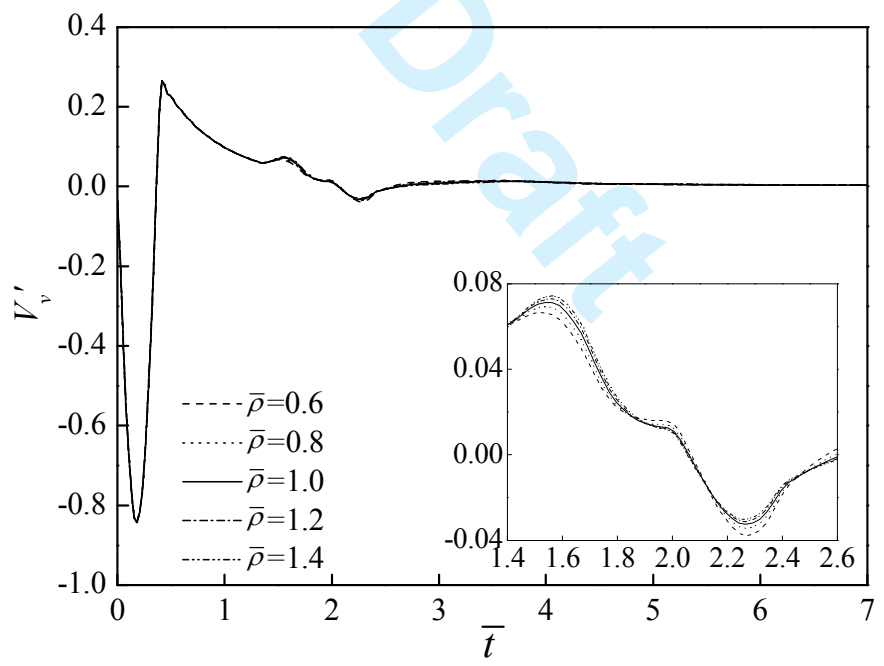

(b) Reflected wave signal curves

Fig. 11 Influence of the density of soil plug on the vertical dynamic response of the pipe pile 


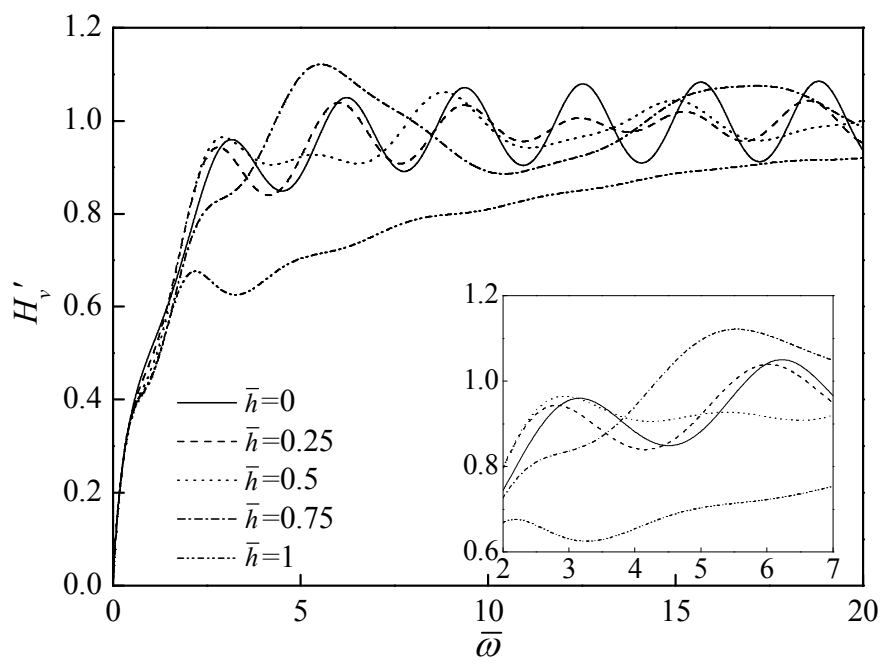

(a) Velocity admittance curves

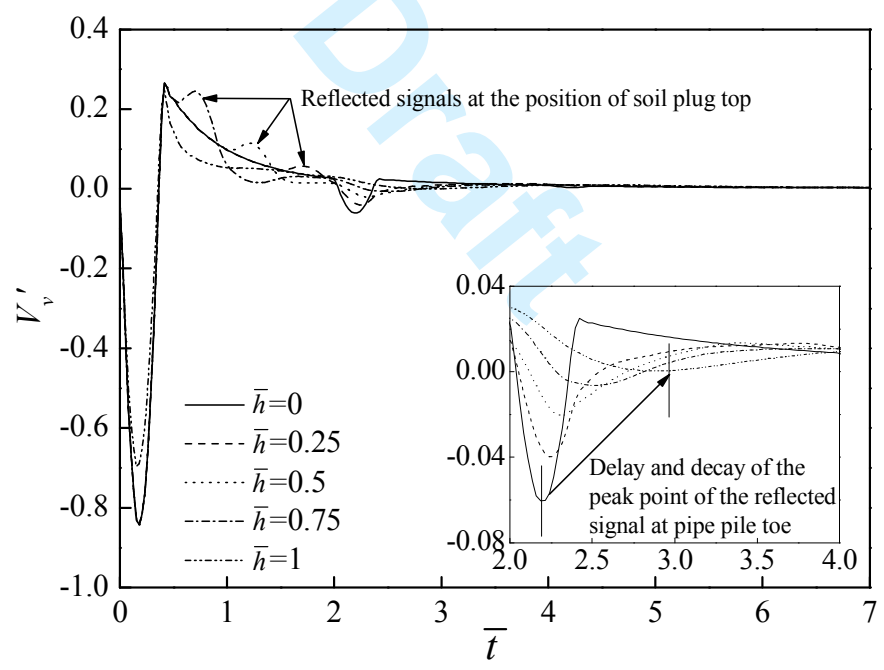

(b) Reflected wave signal curves

Fig. 12 Influence of the height of soil plug on the vertical dynamic response of the pipe pile 


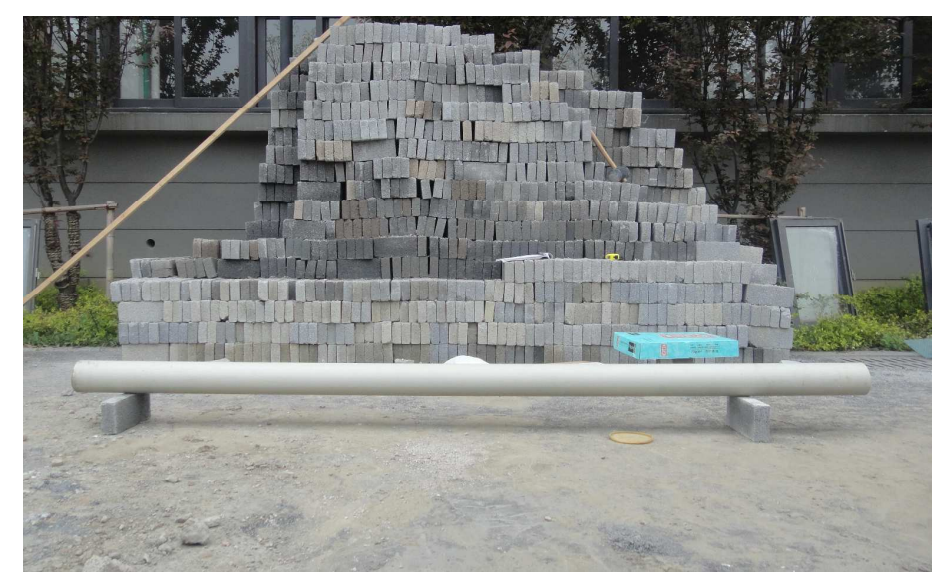

(a) Model pipe pile

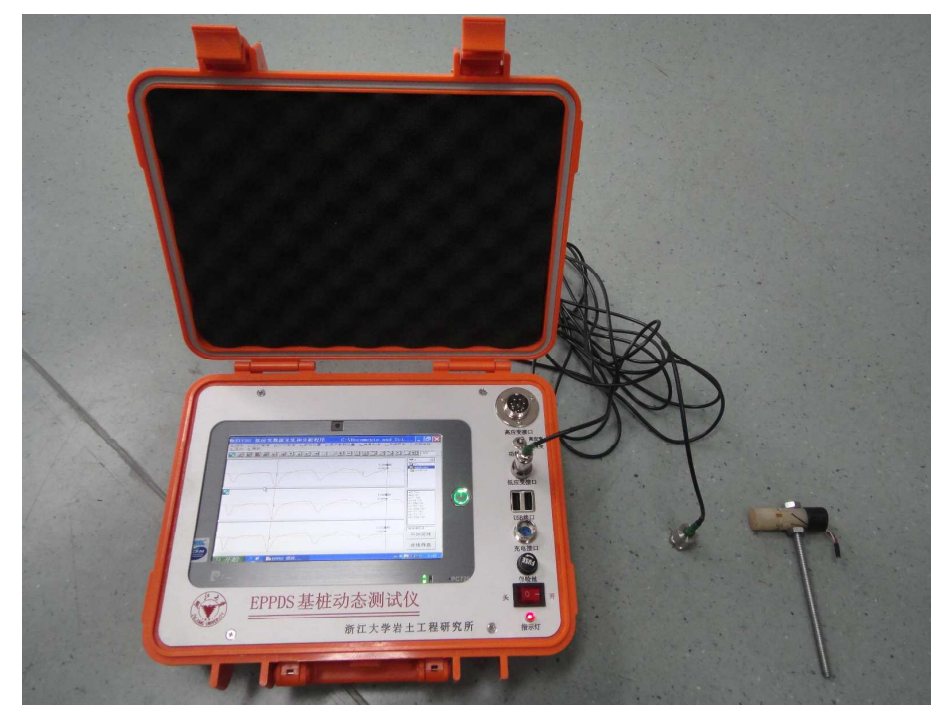

(b) EPPDS Dynamic Testing System of Pile

Fig. 13 Test materials and apparatus 


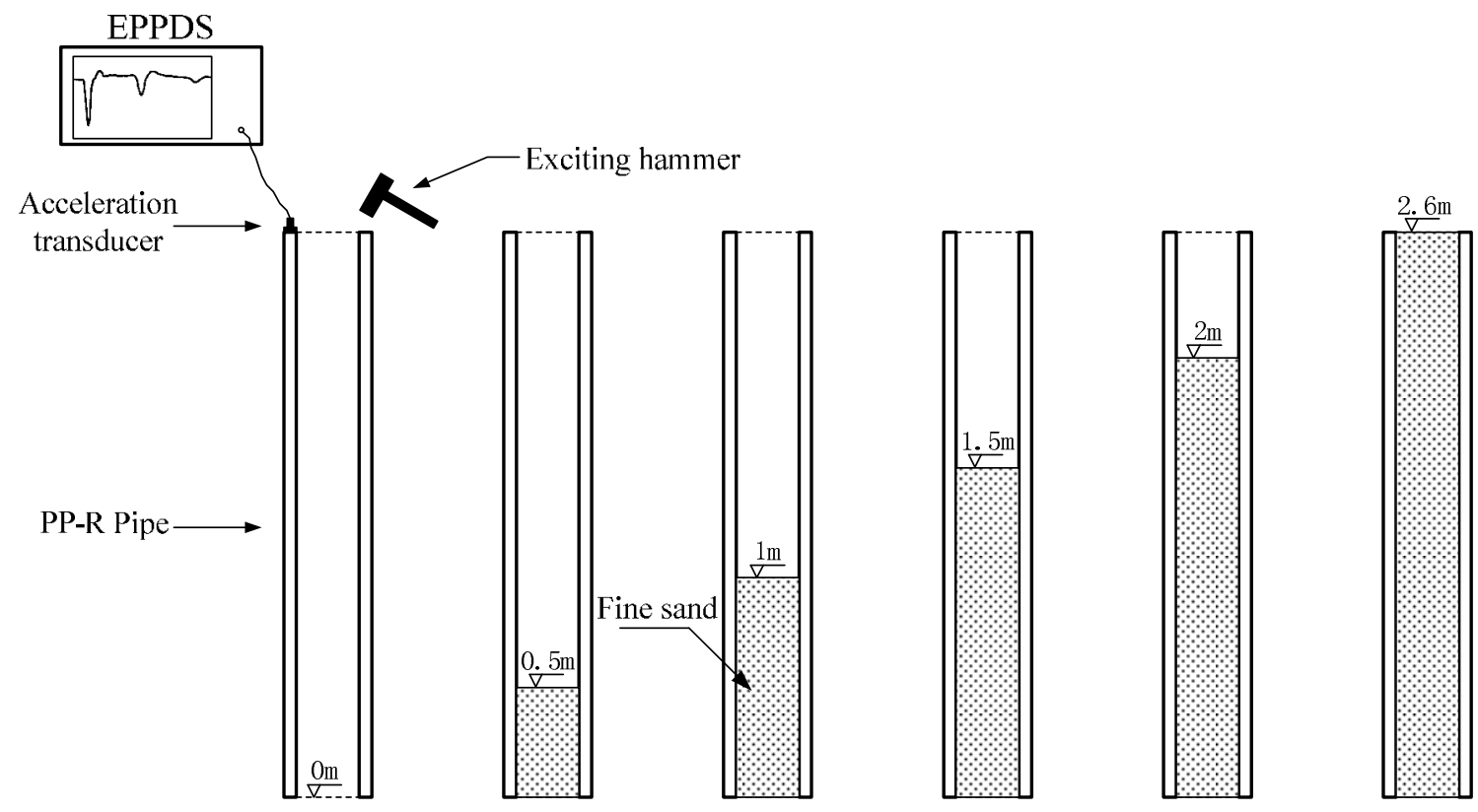

Fig. 14 Schematic diagram of the model test 


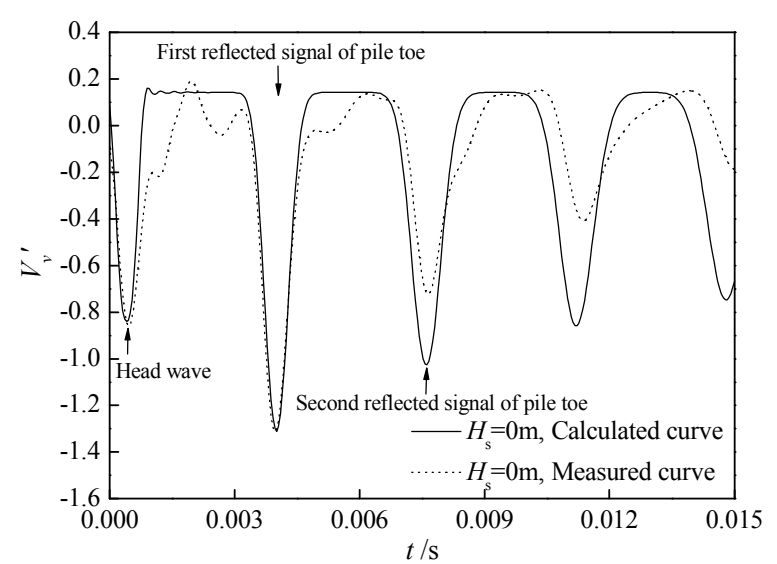

(a) Comparison for the soil plug of height $0 \mathrm{~m}$

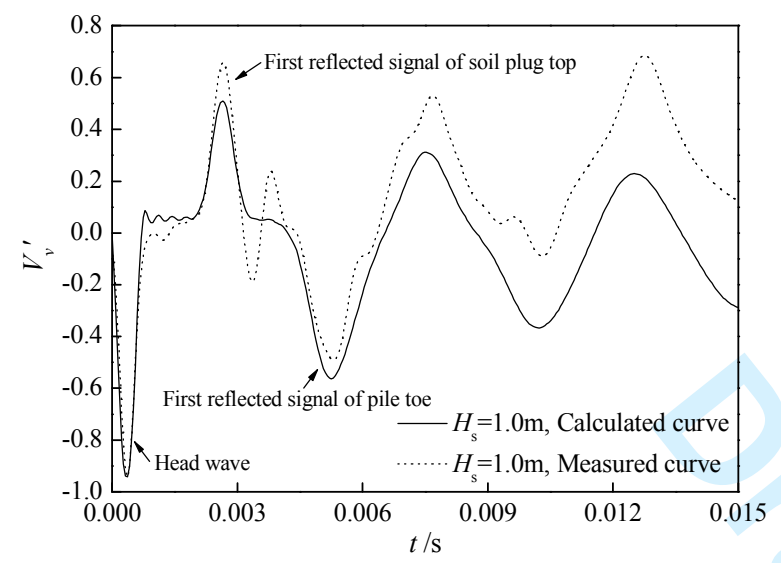

(c) Comparison for the soil plug of height $1.0 \mathrm{~m}$

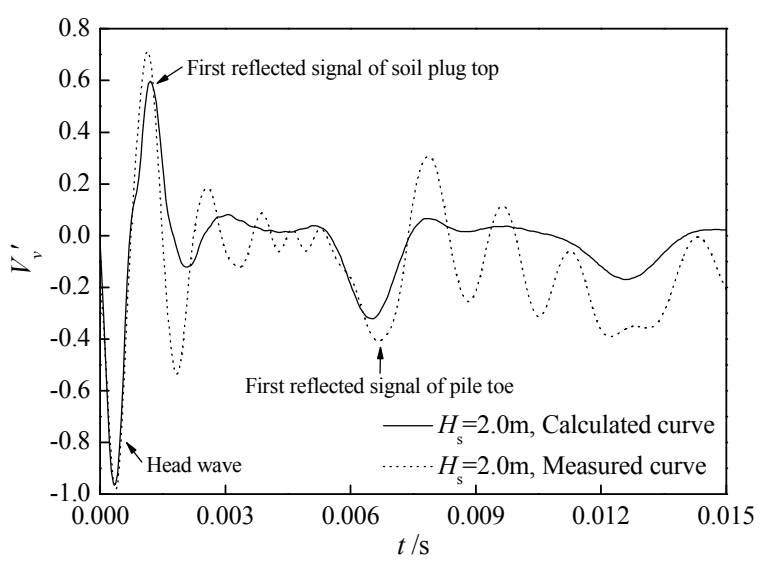

(e) Comparison for the soil plug of height $2.0 \mathrm{~m}$

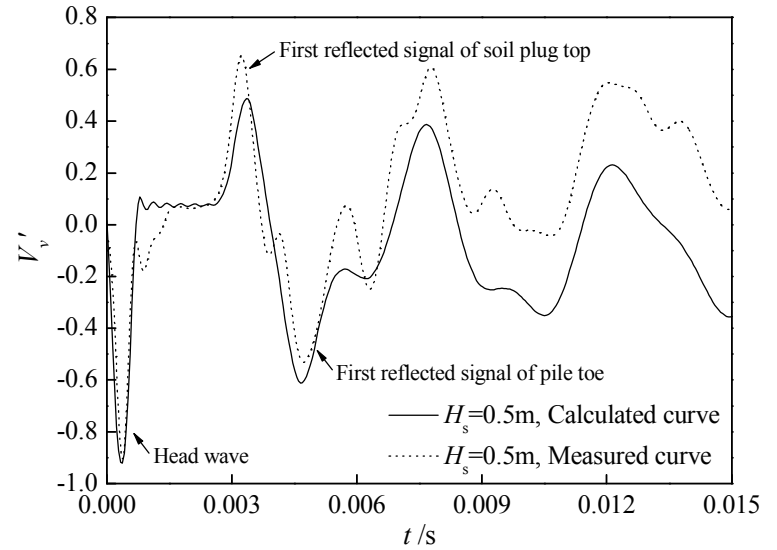

(b) Comparison for the soil plug of height $0.5 \mathrm{~m}$

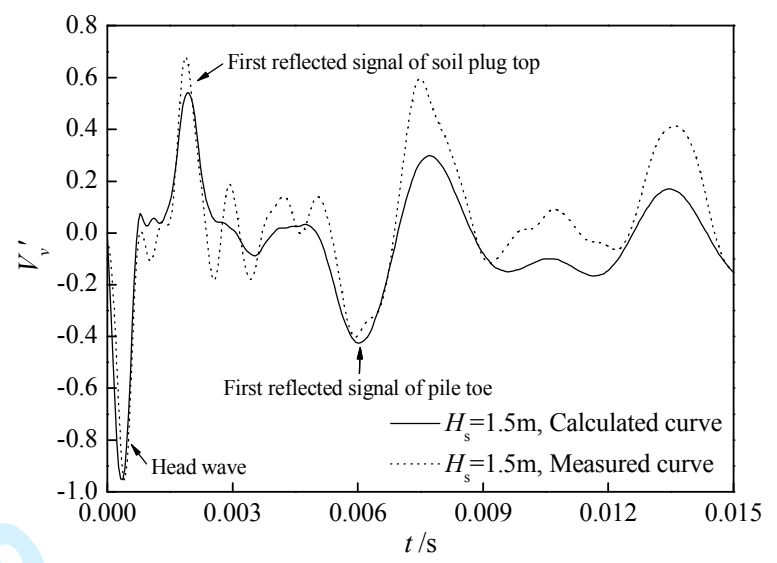

(d) Comparison for the soil plug of height $1.5 \mathrm{~m}$

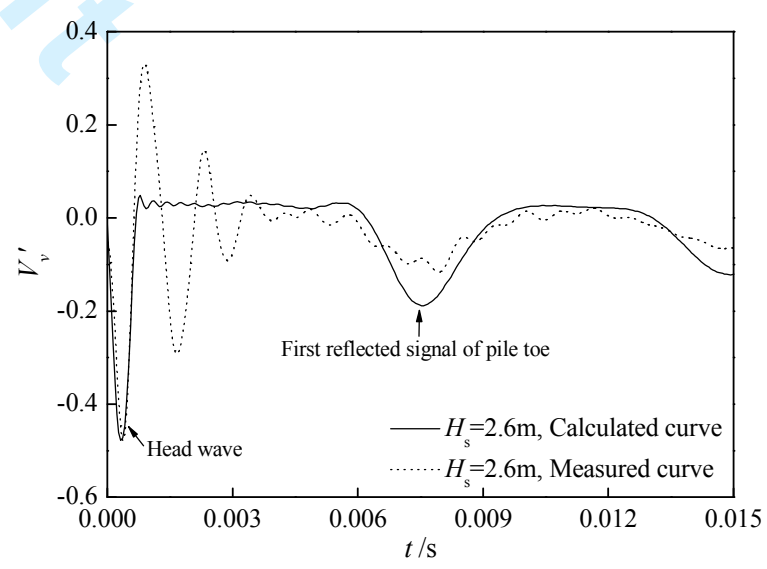

(f) Comparison for the soil plug of height $2.6 \mathrm{~m}$

Fig. 15 Comparison of calculated and measured reflected wave signal curves of model pipe pile 
Table 1 Calculated and measured composite velocity of model pipe pile with/out soil plug

\begin{tabular}{ccccc}
\hline $\begin{array}{c}\text { Height of } \\
\text { soil plug } \\
(\mathrm{m})\end{array}$ & $\begin{array}{c}\text { Calculated } \\
\text { composite velocity } \\
\text { of entire model pipe } \\
\text { pile } \\
\left(\mathrm{m} \cdot \mathrm{s}^{-1}\right)\end{array}$ & $\begin{array}{c}\text { Measured composite } \\
\text { velocity of entire } \\
\text { model pipe pile } \\
\left(\mathrm{m} \cdot \mathrm{s}^{-1}\right)\end{array}$ & $\begin{array}{c}\text { Calculated composite } \\
\text { velocity of pipe pile } \\
\text { segment with soil plug } \\
\left(\mathrm{m} \cdot \mathrm{s}^{-1}\right)\end{array}$ & $\begin{array}{c}\text { Measured composite } \\
\text { velocity of pipe pile } \\
\text { segment with soil plug } \\
\left(\mathrm{m} \cdot \mathrm{s}^{-1}\right)\end{array}$ \\
\hline 0 & 1400 & 1400 & - & - \\
0.5 & 1211.8 & 1206.2 & 782.5 & 763.4 \\
1.0 & 1063.3 & 1053.3 & 771.3 & 754.3 \\
1.5 & 912.6 & 929.5 & 727.3 & 745.7 \\
2.0 & 811.7 & 824.2 & 720.8 & 733.7 \\
2.6 & 717.6 & 726.4 & 717.6 & 726.4 \\
\hline
\end{tabular}

